\title{
Pricing for Medicine Innovation: A Regulatory Approach to Support Drug Development and Patient Access
}

\author{
Rosie Collington" and William Lazonick ${ }^{* *}$
}

\author{
Working Paper No. 176
}

January $28^{\text {th }}, 2022$

\begin{abstract}
The United States represents the world's largest market for pharmaceutical drugs. It is also the only advanced economy in the world that does not regulate drug prices. There is no upper threshold for the prices of medicines in the United States. List prices are instead set by manufacturers in negotiation with supply-chain intermediaries, though some federal programs have degrees of discretion in price determinations. In practice, this deregulated system means that drug prices in the United States are generally far higher than in other advanced economies, adversely affecting patient accessibility and system affordability. In this paper, we draw on the "theory of innovative enterprise" to develop a framework that provides both a critique of the existing pricing system in the United States and a foundation for developing a new model of pricing regulation to support safety and effectiveness through drug development as well as accessibility and affordability in the
\end{abstract}

\footnotetext{
* PhD candidate, University College London Institute for Innovation and Public Purpose; Researcher, The AcademicIndustry Research Network

** President, The Academic-Industry Research Network; Open Society Fellow; Canadian Institute for Advanced Research Fellow; Professor of Economics Emeritus, University of Massachusetts
}

Research for this paper has been funded by the Institute for New Economic Thinking, Open Society Foundations, and Canadian Institute for Advanced Research. We are grateful for comments on previous drafts of this paper from Ekaterina Cleary, Thomas Ferguson, Matt Hopkins, Ken Jacobson, Fred Ledley, Henry Lishi Li, and Öner Tulum. We also wish to thank participants of the workshop at Bentley University Center for Integration of Science and Industry's on 'Reforming the Business of Pharmaceutical Innovation' for their reflections. 
distribution of approved medicines to patients. We introduce a regulatory approach we term "Pricing for Medicine Innovation" (PMI), which departs dramatically from the market-equilibrium assumptions of conventional (neoclassical) economics. The PMI approach recognizes the centrality of collective investments by government agencies and business firms in the productive capabilities that underpin the drug development process. PMI specifies the conditions under which, at the firm level, drug pricing can support both sustained investment in these capabilities and improved patient access. PMI can advance both of these objectives simultaneously by regulating not just the level of corporate profit but also its allocation to reinvestment in the drug development process. PMI suggests that although price caps are likely to improve drug affordability, there remain two potential issues with this pricing approach. Firstly, in an innovation system where a company's sales revenue is the source of its finance for further drug development, price caps may deprive a firm of the means to invest in innovation. Secondly, even with adequate profits available for investment in innovation, a firm that is run to maximize shareholder value will tend to use those profits to fund distributions to shareholders rather than for investment in drug innovation. We argue that, if implemented properly, PMI could both improve the affordability of medicines and enhance the innovative performance of pharmaceutical companies.

\section{https://doi.org/10.36687/inetwp176}

JEL Codes: D2, D4, D8, G3, H3, I1 1, L2, O3

Keywords: Pharmaceuticals, pricing, innovation, strategy, organization, finance, resource allocation, learning, scale, investment, regulation. 


\section{Pharmaceutical regulation for drug innovation}

The United States represents the world's largest market for pharmaceutical drugs. With about 4.3 percent of the world's population, in 2019 the nation constituted 41 percent of the world's $\$ 1.25$ trillion in pharmaceutical drug revenues (Mikulic, 2021). In 2018, it had the highest drug spending per capita at $\$ 1,229$, followed by Switzerland with $\$ 894$, Germany with $\$ 884$, and Canada with $\$ 865$ (see Figure 1).

Figure 1. Per capita spending in USD on pharmaceutical drugs in OECD countries, 2018

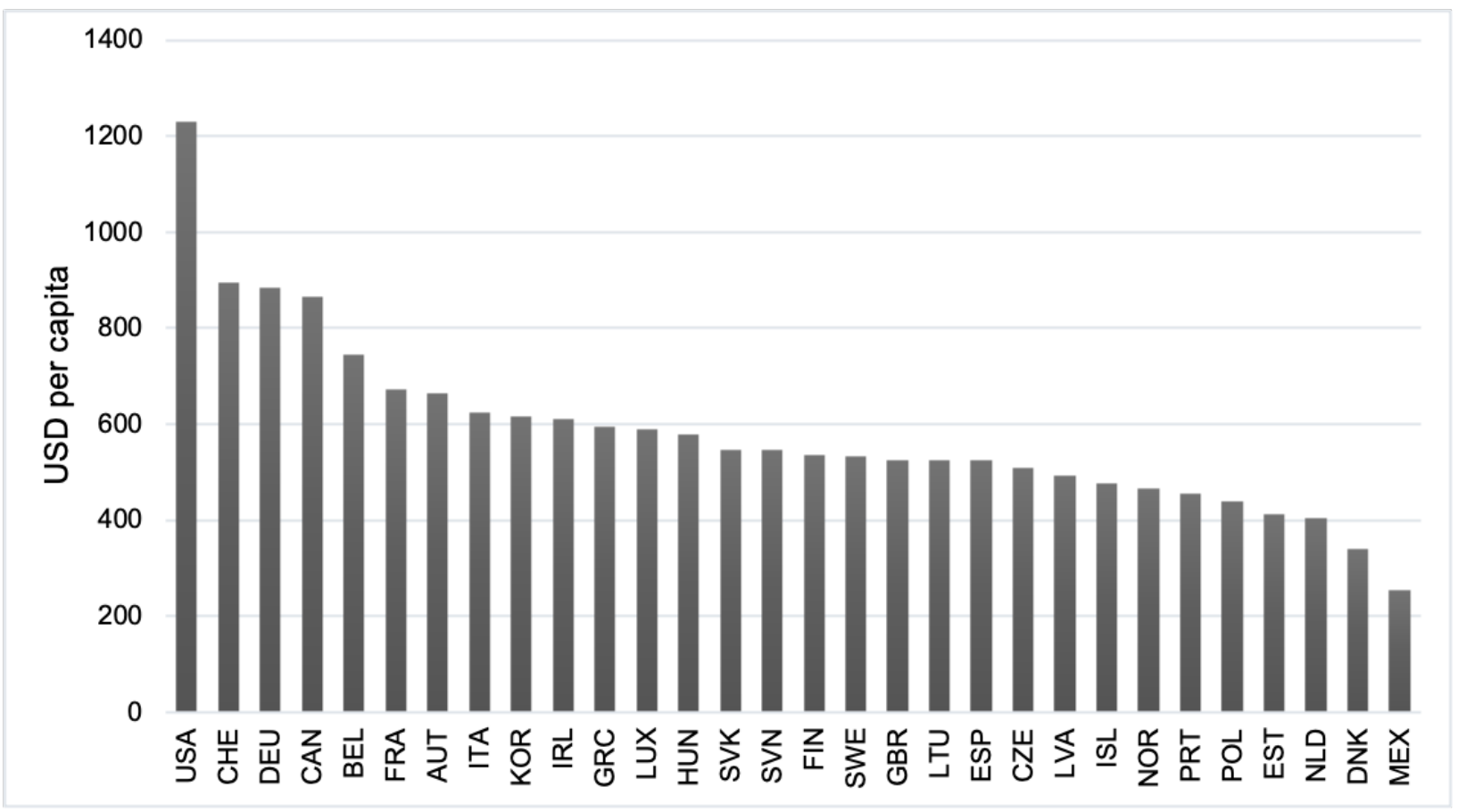

Source: OECD (2020), Pharmaceutical spending (indicator). doi: 10.1787/998febf6-en (Accessed on 05 December 2020)

As a proportion of total US healthcare expenditure, pharmaceutical drugs were 11.3 percent in 2017 (National Center for Health Statistics, 2019, p. 48). Some of this spending is on long-standing prescription medicines, many of which have been off-patent for decades. At the other end of the spectrum, some is on drugs that embody the latest advances in medical therapies. The United States has the world's most robust ecosystem for drug innovation, supported as it is by $\$ 30-\$ 40$ billion in spending annually on life-sciences research by the National Institutes of Health (NIH), many of the oldest and largest Big Pharma companies, and a proliferation of venture-backed biopharma startups (Tulum and Lazonick, 2018). Through the Food and Drug Administration (FDA), the United States has rigorous oversight of approval for use of innovative drugs, seeking to ensure that patients are treated with medicines that are safe and effective.

The United States is also the only advanced economy in the world that does not regulate drug pricing. Indeed, a persistent claim of the US pharmaceutical industry, which we scrutinize closely in this paper, is that these high drug prices are needed to fund and reward investment in innovative medicines. There is no upper threshold for the price of branded medicines in the United States. Although Medicare has some discretion in the determination of prices it pays for prescription drugs, financing more than a quarter of prescription expenditures, at present only the Veterans 
Health Administration and the Department of Defense are formally allowed to negotiate prices directly with drug manufacturers. Mandatory drug-price rebates also exist for Medicaid (True, 2019), and New York has a program that aims at limiting prices for drugs based on their therapeutic value (Frakt, 2021).

In industries characterized by firm-level organizational learning, scale economies, strong intellectual property rights, and a substantial degree of price inelasticity of demand, the senior executives of a dominant firm can often set product prices with a view to achieving what they define as the firm's strategic objectives. The pharmaceutical industry has these characteristics, although, as we shall see, actual drug pricing in the United States is more complicated than simply the senior executives of a patented drug producer setting a price that suits them best.

From the public's perspective, the price that a pharmaceutical company receives for a drug that it controls should reflect its capability to develop, manufacture, and deliver medicines that are:

- Safe: they do not bring harm to patients or inadvertently to others through, for example, the use of environmentally toxic ingredients;

- Effective: they can be proven to lead to improved health outcomes in patient populations;

- Accessible: patients who require a pharmaceutical intervention can obtain the most appropriate course of treatment;

- Affordable: the healthcare system, including government agencies and insured households, can bear the costs of providing patients with the drugs that they require.

In general, we define an innovative product as one that is higher quality (safer and more effective) and lower cost (more accessible and affordable) than a product performing the same function that was previously available. Hence, an innovative pharmaceutical enterprise (which may include more than one company in a partnership) is one that has demonstrated the capability to develop safer and more effective pharmaceutical products, with greater accessibility to the patient population and affordability to the healthcare system. In this paper, we draw upon "the theory of innovative enterprise" (TIE) (Lazonick, 2019, 2010) to explore the implications of high, unregulated drug prices for generating medicines that are safe, effective, accessible, and affordable.

TIE provides a conceptual framework for what we term "pricing for medicine innovation" (PMI), which focuses on the technological, market, and competitive conditions that influence the supply of and the demand for an innovative drug. Lazonick and his colleagues have developed TIE over many years to inform industrial policy, including identification of the ways in which corporate governance approaches that prioritize maximizing shareholder value can inhibit innovation within a firm (in general: Lazonick and O'Sullivan, 2000; Lazonick, 2010, 2012, 2019; and with specific reference to pharmaceuticals: Lazonick and Sakinç, 2010; Lazonick and Tulum, 2011; Lazonick et al., 2017; Tulum and Lazonick, 2018).

We contend that, guided by TIE, a PMI regulatory approach can achieve superior performance to the safety, efficacy, accessibility, and affordability of medicines produced under the existing regime of unregulated drug prices. The objectives of regulation must be to ensure that firms in the industry generate products that benefit households by developing, manufacturing, and delivering 
higher-quality, lower-cost drugs. The PMI approach to drug pricing reflects a long tradition in academic economics that posits that an economy should be run for the benefit of its households. To do so, we argue, government policy must support innovative enterprise and prevent, as we shall explain, the undermining of innovation by corporate financialization.

In most countries, it is health insurers that must agree to pay for prescription drugs. In many advanced economies, excluding the United States, the insurer is a single-payer healthcare system, which regulates drug prices. In the United States, there exist many health-insurance companies, ${ }^{1}$ the largest of which are operated as for-profit businesses (American Medical Association, 2021). In the absence of government price regulation in the United States, prices for pharmaceutical drugs are set by manufacturers in negotiation with insurance companies, ostensibly mediated by pharmacy benefit managers (PBMs). According to one study of the US pharmaceutical distribution system, "for every $\$ 100$ spent at retail pharmacies, about $\$ 17$ compensates for direct production costs, $\$ 41$ accrues to the manufacturer ( $\$ 15$ of which is net profit), and $\$ 41$ accrues to intermediaries in the distribution system: wholesalers, pharmacies, pharmacy benefit managers and insurers (with $\$ 8$ of net profit split among them)" (Sood et al., 2017). Health-insurance companies, which provide coverage to around 67 percent of the population, and in theory should be interested in driving down prices, may be able to force patients to bear the higher costs of drugs resulting from list price increases in the form of higher co-pays and premiums (Kaiser Family Foundation, 2019, pp. 156-158). Insurance plans often also receive rebates from drug manufacturers after the point of sale, incentivizing coverage of particular medicines and not others.

As a consequence of the unregulated pricing system, which effectively provides manufacturers in negotiation with their supply chain intermediaries with control of not only access to the market but also price determination of their product, drug prices in the United States are typically far higher than in other advanced economies. A 2019 report from the US House Committee on Ways and Means found that individual drug prices in the United States were, on average, 3.7 times higher than the combined mean of the other eleven countries in the study (US House Committee on Ways and Means, 2019).

The lack of price regulation for branded medicines renders many prescribed treatments unaffordable for individuals with private health insurance or no health insurance. Although patients covered by insurance plans tend not to pay the full list price for their prescription medicines, increases in list prices can result in higher costs of insurance coverage in the form of deductibles, co-pays, and premiums. A Kaiser Family Foundation report from 2019 indicated that the average premium for family health-insurance coverage nationally increased by 22 percent over the period 2014 to 2019, while average earnings of the insured families increased by just 14 percent (Kaiser Family Foundation, 2019, pp. 30-42). The same report showed that the average annual deductible for health-insurance coverage grew by 36 percent over these five years (ibid., p. 108).

Thus, even when a drug is accessible within the healthcare system, a prescription may not be affordable for the individual or family, insofar as it can place pressure on the ability to pay for other necessities. Despite an overall reduction in the number of uninsured Americans following

\footnotetext{
${ }^{1}$ We use the term "health-insurance companies" as shorthand to describe the non-governmental for profit and not-forprofit entities that provide coverage to around 67 percent of the United States population, usually through an employer (see Tikkanen et al., 2020, for an overview of different types of insurance companies).
} 
the introduction of the Affordable Care Act (ACA) in 2010 (Tolbert et al., 2019, p. 2), in 2019, 26.1 million people, or eight percent of the population, were not covered by an insurance plan at any point during the year (Keiser-Starkey and Bunch, 2020, p. 3). Coverage is particularly low in the 12 states that have not opted to expand Medicaid to low-income Americans, as called for in the ACA (Cohen et al., 2018; Kaiser Family Foundation, 2022). In most cases, uninsured individuals need to pay out-of-pocket for healthcare costs. Many prescription medicines are too expensive for those without health insurance, and these individuals are more likely than those with insurance to report cost-associated nonadherence (Kennedy and Morgan, 2006).

Such evidence supports the contention that pharmaceutical drugs are much less affordable to US patients than they would be with a regulated pricing system. The existence of a business-sector health-insurance market also presents a barrier to drug accessibility in two key ways. Firstly, the inclusion of a drug in a coverage plan's formulary is, as noted, influenced by financial agreements between the manufacturer and insurance company, which are kept secret. Secondly, because the costs of insurance coverage remain largely determined by the business-sector insurance company, even after the introduction of the ACA, whether a patient can access a drug depends on how expensive their coverage is in relation to their wages and other necessary expenses. If someone cannot afford a health-insurance policy, the drugs that it covers are inaccessible. Thus, a further means of improving accessibility would be the creation of a single-payer healthcare system. We suggest that, while PMI could be introduced within the existing structure of business-sector health insurance, it nonetheless points to the obsolescence of that structure.

TIE recognizes the centrality of collective investments by government agencies and business firms in the productive capabilities that underpin the drug development process (Hopkins and Lazonick, 2014). We show that rational drug-price regulation can be used to support investment in drug innovation while enhancing patient access and affordability. PMI can be particularly effective in the United States where most major pharmaceutical companies do not use augmented profits from elevated drug prices to augment drug development spending, as is usually assumed. Many pharmaceutical companies use-or more correctly abuse-high prices to support the incomes of shareholders through cash dividends and stock buybacks at the expense of investment in drug innovation or making the drugs that have already been commercialized more accessible and affordable (Lazonick et al., 2017; Lazonick et al., 2019). The largest for-profit insurance companies-UnitedHealth, CVS Health (which owns Aetna), Anthem, and Cigna — also engage in large-scale stock buybacks to prop up their stock prices. Also, as discussed in this paper, the largest PBMs, which play significant roles in pricing drugs, are now owned by CVS Health (Caremark), Cigna (Express Scripts), and UnitedHealth (OptumRx) (Fein, 2021).

How, then, do the US pharmaceutical industry and its advocates justify unregulated drug prices? We identify four distinct, but not mutually exclusive, arguments that these interests make for the status quo absence of regulation for drug pricing in the United States:

Argument 1. High drug prices are needed so that a pharmaceutical company has sufficient profits to fund future drug development.

Argument 2. Expectations of high corporate profits yielded by setting high drug prices incentivize financiers to make the risky investments needed for drug innovation. 
Argument 3. New drugs save patients' lives and therefore provide value for money, even if they are expensive.

Argument 4. Other actors in the supply chain, and not the manufacturers, capture the higher profits from higher drug prices.

Drawing on TIE, we address each of the arguments to show that, given the innovation objectives of pharmaceutical companies, as well as the technological, market, and competitive characteristics of the pharmaceutical industry, there exists no coherent rationale for unregulated pricing. Even insofar as these four arguments have some merit, we show that PMI represents a far more appropriate model for drug pricing than the current approach.

In the next section of this paper, we introduce PMI as an approach to pharmaceutical drug pricing based on the conceptual framework derived from TIE. Equipped with the theory of innovative enterprise and our novel pricing approach, we then examine and challenge the four arguments outlined above that have been made by pharmaceutical companies, their trade groups, and academic advocates against pharmaceutical price regulation in the United States. We then outline the capabilities which a government regulatory agency would require in order to implement the PMI approach. We conclude the article by summarizing the specific analytical insights that can be drawn from TIE to regulate pharmaceutical companies and their products in the United States and in nations around the world.

\section{The Theory of Innovative Enterprise as a Drug-Pricing Framework}

\subsection{The social conditions of innovative enterprise}

The development, manufacture, and delivery of a safe, effective, accessible, and affordable medicine is an innovation process. As in all innovation processes, its essence in pharmaceuticals is the organizational learning that is required to create a higher-quality (safer and more effective) product than had previously been available. The innovation process is uncertain, collective, and cumulative, with direct implications for the strategy, organization, and finance of the pharmaceutical company that seeks to generate an innovative drug.

- The innovation process is uncertain: When a business firm makes investments in transforming technologies and accessing markets, the success or failure of the investment strategy cannot be known; if the product and financial outcomes were known, the process would not be innovation. Uncertainty may be technological (is the development of a higher-quality product possible?), market (is there accessible demand for a higher-quality product?), and/or competitive (will a rival firm generate a superior product?). This uncertainty creates the need, within an innovative enterprise, for the exercise of strategic control to make investments in productive capabilities that enable the firm to confront and possibly overcome uncertainty.

- The innovation process is collective: To generate a higher-quality, lower-cost product, the firm must integrate the skills and efforts of large numbers of people within a complex 
hierarchical and functional division of labor into the learning processes that are the essence of innovation. These interactions involve first and foremost direct employees but can also include those who work for other business firms (functioning as collaborators, suppliers, and distributors) as well as for government agencies and civil-society organizations. This collective learning is the key to overcoming the uncertainty inherent in the innovation process, and it is accomplished within the firm through organizational integration.

- The innovation process is cumulative: Collective learning today enables collective learning tomorrow, and these organizational-learning processes must be sustained continuously over time until, through the development, manufacture, and delivery of an innovative product, revenues can be generated. The firm requires an uninterrupted cash flow to finance the innovation process. Equity investments, debt issues, unremunerated labor, and government subsidies can provide sources of funds to sustain the innovation process in the period before the firm possesses a revenue-generating product. If and when, through the sale of a product, average unit revenue exceeds average unit cost, the firm has the option of using the resultant profit as a source of funds for further investment in its productive capabilities. Investment in collective and cumulative learning processes that can result in a product that is both higher quality and profitable require financial commitment.

Within the TIE framework, strategic control, organizational integration, and financial commitment are the three "social conditions of innovative enterprise" (Lazonick, 2019, 2010) that can enable the firm to manage the uncertain, collective, and cumulative character of the innovation process, with the objective of generating a higher-quality, lower-cost product than was previously available.

- Strategic control: For innovation to occur in the face of technological, market, and competitive uncertainties, executives who control corporate resource allocation must have the abilities and incentives to make strategic investments in innovation. Their abilities depend on their knowledge of how strategic investments in new capabilities can enhance the firm's existing capabilities. Their incentives depend on alignment of their personal goals with the firm's purpose of generating innovative products.

- Organizational integration: Implementation of an innovation strategy requires the integration of people with different hierarchical responsibilities and functional capabilities into collective and cumulative learning processes. Employment stability, promotion opportunity, work satisfaction, and enhanced remuneration are critical for motivating and empowering employees to engage in collective learning within the firm over a sustained period of time.

- Financial commitment: For collective learning to accumulate over time, the sustained commitment of patient capital must keep the learning organization intact. For a startup company which lacks a profitable product, venture capital can provide financial commitment. For a going concern that has one or more profitable products, retained 
earnings (leveraged, if need be, by debt issues) from those profits are the foundation of financial commitment.

We can conceptualize the implications of TIE for addressing the question of product price regulation by translating the social conditions of innovative enterprise into a supply-and-demand framework that relates the cost of the development, manufacture, and delivery of a product to the revenue that a commercialized product can eventually generate. Armed with TIE, we can then research the particular technological, market, and competitive conditions that characterize the industry concerned - in this case, pharmaceuticals - and the particular type of product within that industry in structuring the supply (cost) and demand (revenue) conditions for considering the appropriate product price for supporting drug development and patient access. ${ }^{2}$

As we shall explain, the supply-demand analysis, as applied to pharmaceuticals, does not (as in conventional theories of price determination) yield an "optimal" price. Rather, it provides a point of departure for setting a regulated price that supports innovation in the form of a safer, more effective, more accessible, and more affordable medicine.

Strategic control affects the firm's cost structure because a) an innovative investment strategy is not only product-specific but also firm-specific; b) an innovative investment strategy entails fixed cost, the level of which is dependent on not only the size but also the duration of the investment in innovation; and c) the failure of any particular investment strategy to generate an innovative product is always possible. Where innovation is concerned, there is no "optimal" investment strategy, and, for better or for worse, the particular strategy that is implemented depends on resource-allocation decisions made by those people who exercise strategic control.

In pharmaceuticals, the investment strategy depends on the particular disease indication for which the firm seeks to develop, manufacture, and deliver a treatment or a cure. For any given indication, there are many different investment strategies that a pharmaceutical firm can adopt. The cost of implementing each of these investment strategies differs, depending on the types of learning processes in which senior executives as strategic managers decide to invest; their capabilities in managing organizational-learning processes; and the financial resources that they can mobilize to sustain these learning processes over time. Even in the same industry and institutional environment, firms that seek to innovate in the same product area will have different cost structures because of identifiable firm-specific differences in the social conditions of innovative enterprise.

Fixed cost is defined as a cost that a firm incurs irrespective of the output that it sells. In the "textbook" theory of the firm, economists view investment in plant and equipment as the source of fixed cost and the employment of labor as a variable cost that can be increased or reduced as more or less of the firm's output is needed to be supplied to the market (cf. Lazonick, 2022). From the TIE perspective, insofar as the productive capability of the firm depends on organizational learning, labor engaged in this learning becomes a component of fixed cost; the cumulated capabilities of the people in whose organizational learning the firm invests are assets, the cost of which must be incurred irrespective of the amount of the firm's output that the expenditure makes possible. In pharmaceuticals, research and development (R\&D) expenditures capture a critical part

\footnotetext{
${ }^{2}$ For a pioneering empirical effort to engage in such as approach, focusing on sofosbuvir, see Roy, 2017.
} 
of the fixed cost of investment in people for the purpose of drug development and approval. ${ }^{3}$ But organizational learning occurs in virtually all of a firm's functional activities, including the manufacture and marketing of drugs. Fixed-cost investments in human assets are pervasive in the pharmaceutical industry.

The more complex the organizational-learning processes to develop a safe and effective drug, the greater is not only the size of the investment in the productive capabilities of employees that must be made but also the duration of time that the investment must be sustained until a drug is approved by the FDA for commercialization. Therefore, the fixed cost of drug development cumulates over time. The firm may choose to develop the drug in-house or it may gain access to the requisite organizational learning through acquisitions or strategic alliances (which may be with other businesses but also government agencies and academic labs). Whatever the interactive network may be, the firm needs to integrate people into organizational learning processes by providing them with employment security, remuneration incentives, and complementary physical resources in the form of plant, equipment, and materials.

\subsection{High fixed cost in the development of a higher-quality product}

Given the extent to which drug development is uncertain, collective, and cumulative, the foundation for a pharmaceutical company to invest in the development of an innovative drug is generally prior investment in medical knowledge by government agencies that, unlike business firms, do not have to be profitable to survive.

With its National Institutes of Health (NIH), the United States is the global leader in publicly funded life-sciences research to support the development of pharmaceutical medicines. The 2021 budget of the NIH was $\$ 42.9$ billion, and since 1938, when NIH expenditures were first recorded, total funding has been over $\$ 1.2$ trillion in 2021 dollars (National Institutes of Health, 2022). Without this large-scale and persistent government support, the pharmaceutical industry in the United States as we know it would not exist (Cleary et al., 2020; Tulum and Lazonick, 2018).

The US government also supports the pharmaceutical industry through the nation's patent system, which provides a company with 20 years of protection against competition in developing and commercializing the patented drug. In addition, the Orphan Drug Act of 1983 grants market exclusivity and subsidies to companies that develop medicines for rare and genetic diseases (Tulum and Lazonick, 2018). State and local governments often provide pharmaceutical companies with tax breaks as inducements for local investments in research and manufacturing facilities, even as many firms seek to avoid taxes in their key geographic markets, including the United States (Fried, 2018).

On top of that, US federal, state, and local governments invest in educational systems that, among many other things, prepare people to pursue careers in life sciences, working in business firms,

\footnotetext{
${ }^{3}$ It is obvious that R\&D expenditure represents fixed cost: an investment incurred irrespective of the amount of output that the expenditure makes possible. Yet, in contrast to investments in plant and equipment, by most accounting conventions, R\&D expenses are treated as current operating costs that are fully attributed to current sales. The reason, we believe, is that human assets cannot be owned and hence cannot appear on balance sheets. The economic reality is, however, that a firm's investment in the capabilities of its employees represents a fixed cost, not a variable cost.
} 
government agencies, and civil society organizations. The United States has long had the world's foremost system of higher education in life sciences, attracting talented people from around the world as faculty and students. In 2016, the nation's system of higher education graduated 768,000 students with science and engineering bachelors' degrees and about 40,000 with science and engineering PhDs (National Science Board, 2020). About one third of the doctoral degrees were earned by foreign students on temporary visas, but between 2003 and 2017 the proportion of these PhDs who stayed working in the United States for at least five years after graduation ranged from 64 percent to 71 percent (ibid., p. 5).

Absorbing this government investment in life-sciences knowledge, strategic control over the allocation of resources to drug development generally resides within a business corporation. Historically, prior to the $1980 \mathrm{~s}$, the leading pharmaceutical companies grew to be dominant by offering employees the prospect and reality of a career with one company (Lazonick et al., 2014). Besides accumulating formidable capabilities for the manufacture and delivery of medicines, these companies organized world-class research labs, staffed by first-rate scientific personnel, most of whom would remain with the company over the course of their careers (Chandler, 2009).

From the late 1970s, as a result of the invention of recombinant DNA (Hughes, 2011) and the rise of venture-capital institutions related to the ongoing microelectronics revolution (Lazonick, 2009), large numbers of startup biopharma companies emerged that could lure away scientists from secure careers with established pharmaceutical companies by offering them abundant stock options, which were low-cost from the startup's perspective, and which could be highly lucrative for employed individuals if and when the company would do an initial public offering (IPO) on the NASDAQ stock exchange (Lazonick and Tulum, 2011). The movement of scientists out of the research labs of large companies to startups undermined the productivity of "Big Pharma" R\&D while at the biopharma startups a listing on NASDAQ within years of a company's founding could make scientists, along with financiers, very wealthy, even when their collective learning efforts remained years away from developing a drug that could be commercialized (Lazonick and Sakinç, 2010).

Alternatively, the stock price of a young biopharma company could soar with the acquisition of the firm by an established pharmaceutical company. It could then be challenging for the acquiror to sustain the organizational-learning processes when scientists from the startups who had realized significant wealth from stock options or stock awards at the acquisition worked side by side with pharmaceutical industry scientists whose monetary rewards depended on their "career-with-one company" salaries. Within this "dual economy" structure of the $21^{\text {st }}$-century pharmaceutical industry, the need to manage drug development through organizational integration remains, but it has become far more complex than it was when pharmaceutical companies could secure a stable scientific labor force as career employees (Tulum, 2018; Tulum et al., 2022; Tulum and Lazonick, 2018).

These management issues of the relation between the social organization of the firm and its productive capabilities are complicated further by the fact that the pharmaceutical industry is now global. Some of the most innovative companies are based in Europe, but they control significant operations in the United States, often as the result of US-based acquisitions. Governance, employment, and investment institutions that prevail in the home nations of large pharmaceutical companies affect their operation and performance, including how they integrate foreign acquisitions (Tulum and Lazonick, 2018). That is, within nations, distinctive institutions influence 
organizational-learning processes, and transnational pharmaceutical companies often must manage different systems of organizational learning based on differences in national institutions.

If and when the FDA grants approval for the use of a drug, the pharmaceutical company that controls the manufacture and marketing of the drug can then seek to transform the high fixed cost incurred in developing the drug into a low unit cost by reaping economies of scale through the delivery of the drug to large numbers of patients, via intermediaries, such as insurance companies and PBMs, as discussed below. The firm incurs additions to fixed cost in making the drug accessible to patients through investments in facilities and personnel for mass production (including the cost of maintaining quality as the firm scales production) and mass distribution. Given the firm's fixed cost of developing, manufacturing, and delivering the drug, the greater the number of patients to whom the firm sells the product, the lower the unit cost of the product, and hence the more potentially affordable the drug, with actual affordability to government agencies and patients' households depending on how the drug is priced.

This transformation of high fixed cost into low unit cost is represented in the cost curve in Figure 2. In line with our discussion, a firm's social conditions of innovative enterprise will influence the position and shape of the cost curve as it unfolds over time. Note that given publicly funded government investment in knowledge embodied in drug development, the firm's cost structure does not usually come close to fully accounting for the social cost of bringing a drug to market. Moreover, the unit cost of a drug is only meaningful when output is delivered to patients. Given the uncertainty of the innovation process, a drug candidate in which the firm invests may fail to yield a safe and effective product that can be submitted for FDA approval, in which case the firm can incur substantial fixed cost without a transformation into low unit cost.

Figure 2. The innovating firm's cost curve for a pharmaceutical drug

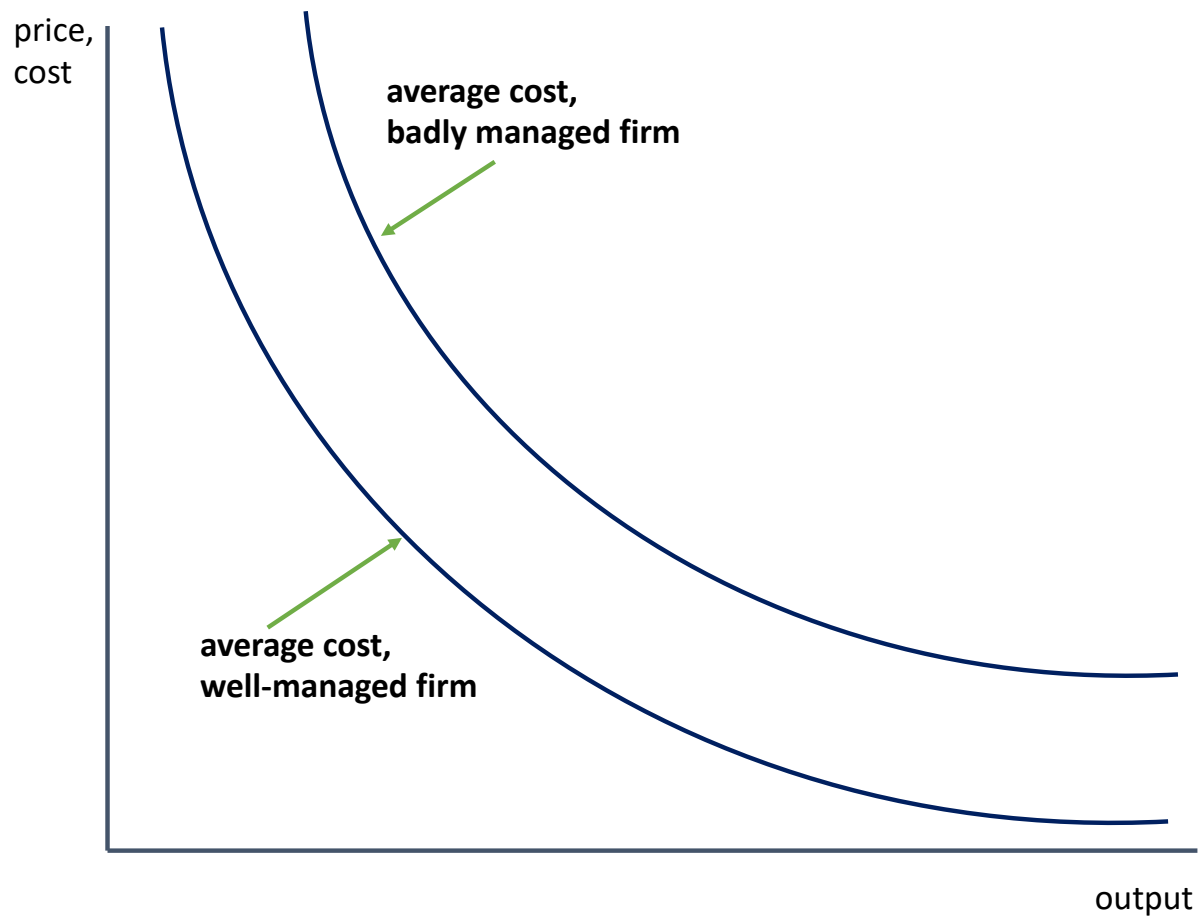


Organizational integration affects the firm's cost structure because the fixed cost of organizational learning required for innovation entails the attraction, motivation, retention, and rewarding of people who must interact productively as members of a complex division of labor over a sustained period of time. As a social condition of innovative enterprise, organizational integration can be well managed or badly managed. It is well managed when the employees involved apply their skills and efforts to the achievement of the firm's goal of generating an innovative product. It is badly managed when employees, in whose productive capabilities the firm may have invested, are unproductive in their interactions within the firm or, alternatively, leave the firm, presumably to use their productive capabilities elsewhere.

Note that a determination of whether or not a learning process is well-managed depends on benchmarking to best practice of the process itself-for example, clinical trials - and not necessarily on the product outcome. Given the uncertainty of drug development, a well-managed learning process may fail to generate a safer and more effective medicine. A badly managed learning process may succeed in generating a safer and more effective drug, but only at a very high fixed cost, well in excess of the expenditure required by best practice. Nevertheless, all other things equal, well-managed organizational integration increases the probability of generating a safe and effective drug while reducing the probable organizational-learning cost to develop, manufacture, and deliver the drug.

For a given pharmaceutical firm, the assessment of the fixed cost of developing an approved drug should include a normal failure rate by a well-managed firm. Even in the best-managed firm, it is normal for drug development projects to fail to generate approved drugs. But the firm's bad management of drug development should not be rewarded by higher regulated prices on approved drugs, as would be the case if the regulator used as a starting point for price setting the "badly managed firm" cost curve in Figure 2.

Some of the organizational learning in the innovation process occurs externally to the pharmaceutical company that seeks to commercialize the drug. It can acquire external learning through the merger with or acquisition of other firms or, alternatively, through subcontracting and licensing arrangements. The cost of these deals may be inflated by competition with other pharmaceutical companies for control of this intellectual property, especially when corporate stock rather than cash is used as a "combination currency", as has happened increasingly in recent years (Lazonick et al., 2017; Roy, 2020). The regulator should not pass this asset inflation through to the acquirer's drug price, if and when the drug gains FDA approval. By the same token, price regulation that discounts such asset inflation should serve to dampen speculative bidding for intellectual property held by other firms in the prior process of drug development.

The innovating firm does not necessarily pay for all of the fixed cost required to generate an innovative drug. Much of the learning is in the public domain, available in academic journals and government reports. The US government, through the NIH, funds much of the training and employment of a significant proportion of the people who produce these publications. A regulated drug price should preclude the firm from capturing the value gains from publicly funded knowledge that is free or below cost to the pharmaceutical firm.

That having been said, the integration of public knowledge into the firm's innovation process is not costless. The integration of external knowledge depends on the firm's "absorptive capacity" (Cohen and Levinthal, 1990)_or more accurately, "absorptive capability". Furthermore, given the 
relation between large pharmaceutical companies and biopharma startups that has come to characterize the pharmaceutical industry, absorptive capability is also required to integrate mergers and acquisitions into the firm that now exercises strategic control. Investment in absorptive capability increases the firm's fixed cost, although the better managed the firm, the more it can absorb productive learning for a given cost. As in the case of organizational learning internal to the firm, the regulator must understand best practice in valuing the external knowledge that a firm integrates into its internal learning processes. This knowledge is developed through investment in the regulator's capabilities, as we will discuss shortly.

Financial commitment affects the firm's cost structure because different sources of finance entail different financial costs related to both the rate of interest per unit of finance and the securityi.e., degree of commitment - of the source of finance over time. If the source of finance is not secure, its withdrawal can disrupt the collective and cumulative learning process that is the essence of innovation. For a business that is already profitable, the least expensive source of finance for investment in innovation is the earnings that the firm retains out of profits. The more periods (e.g., years) over which the firm can generate a continuous profit stream out of which it can retain earnings, the more available to the firm is this form of financial commitment. These retained earnings can then be leveraged with long-term bond issues, with high and persistent retention rates enabling the firm to access debt on more favorable terms. Excessive debt can, however, undercut a retention stream by placing an overly heavy financial charge on profits.

Cash dividend payments may be a legitimate distribution from profits when the firm has been able to generate a steady profit stream, sufficient to fund investment in innovation. Excessive dividends, however, can impinge on the financial commitment required for drug innovation. Distributions in the form of stock buybacks done as open-market repurchases are far more egregious because their purpose is to manipulate the company's stock price, rewarding those sharesellers who are in the business of timing the buying and selling of shares rather than shareholders, all of whom gain equally in terms of dividends per share for continuing to hold the company's stock. The sharesellers include senior executives with their stock-based pay as well as Wall Street bankers and hedge-fund managers (Lazonick and Shin, 2020).

Öner Tulum's doctoral research, for example, has shown that companies that do more stock buybacks have a lower productivity of R\&D (pipeline products per $\$$ billion in R\&D spending) (Tulum, 2018). More recently, Tulum, Andreoni and Lazonick (2022) have found that, over the past decade, at two UK pharmaceutical companies-AstraZeneca and GlaxoSmithKline - senior executives recognized that they needed to cease buyback activity in order to augment investment in the product pipeline. Beyond its implications for the financial commitment needed to develop innovative pharmaceutical products, the allocation of corporate resources to "maximize shareholder value" also tends to undermine the other two conditions of innovative enterprise: strategic control and organizational integration. In companies that focus primarily on increasing yields to shareholders via dividends and buybacks, senior executives who exercise strategic control over corporate resource allocation tend to eschew uncertain investments in new drug development (Tulum and Lazonick, 2018). The largest proportion of their total remuneration comes from stockbased pay, which in the United States is structured to reward speculation in and manipulation of the company's stock price rather than stock-price gains that reward drug innovation (Hopkins and Lazonick, 2016; Lazonick, 2019; Lazonick et al., 2019). Indeed, senior executives who prioritize value extraction for the sake of shareholder gains may lack the ability to assess the prospects for innovative drug development (see, for example: Lazonick and Tulum, 2015). The failure to 
allocate resources to innovative investment strategies undermines organizational integration, which depends on the opportunity and incentives for the firm's employees to engage in collective and cumulative learning through their participation in innovative drug development projects (Tulum and Lazonick, 2018).

In PMI, a regulator should permit payment of reasonable dividends if the company has displayed a record of prioritizing investment in organizational learning and retention of earnings out of profits, generated by previously successful drugs. That is, payment of dividends should not undermine the firm's organizational integration and financial commitment as social conditions essential to carrying out its innovation strategy. PMI would, however, preclude a pharmaceutical firm from doing stock buybacks as a form of distributing corporate cash to shareholders (Lazonick et al., 2019).

\subsection{Driving down unit cost through economies of scale}

When a pharmaceutical firm is successful in generating a medicine that is safer and more effective than those previously available, it can commercialize the product. Beyond the development of the medicine, the firm will have to make fixed-cost investments in manufacturing facilities to produce sufficient medicine of consistently high quality for the extent of the market able and willing to buy it and to deliver (through intermediaries) the medicine to the facilities (pharmacies, nursing homes, hospitals) that can dispense it to patients. As the medicine is accessed by more patients, the innovating firm spreads out the fixed cost of organizational learning as well as plant and equipment to achieve economies of scale, as depicted by the cost curve for the medicine in Figure 2.

As outlined above, the actual position and shape of the cost curve will reflect a number of factors that determine the amount of fixed-cost investment that the firm must make to bring a safe and effective medicine to market. These factors will include:

- The extent of the prior learning relevant to the development, manufacture, and delivery of the particular medicine that is in the public domain, which the innovative firm can absorb into its own organizational learning at a low fixed cost;

- The cost of gaining access, by licensing intellectual property or acquiring a company, to prior learning by other firms on which organizational learning in the innovating firm can build;

- The size of the in-house learning collectivity in which the innovating firm must invest to generate a safe and effective medicine;

- The duration of the in-house investment in cumulative learning in which the innovating firm must invest to generate a safe and effective medicine;

- The size of complementary investments in plant and equipment required to manufacture a safe and effective medicine;

- The size of complementary investments in marketing and sales personnel and facilities required to deliver a safe and effective medicine.

The development of a safe and effective medicine, which includes clinical trials, is the most expensive and uncertain stage of the drug innovation process, although the fixed-cost investment 
can be reduced by outsourcing some product-development activities, e.g., clinical trials. As indicated by the last two items in the list above, the innovating firm also must make fixed-cost investments at the manufacturing and delivery stages, again with outsourcing of certain activities as a strategy for seeking to reduce fixed cost. Some types of drug production are much more capital- and learning-intensive than other types, and hence the extent of the market required to achieve the economies of scale that make a drug affordable may be much greater in some cases than in others. There is also learning-by-doing in drug manufacture that can potentially drive down unit cost as the extent of the product market expands.

In the delivery stage, a drug company must make fixed-cost investments to bring a drug to market. A drug company can also engage in learning-by-using, gathering and analyzing patient data that can further improve the safety and effectiveness of an approved medicine. Indeed, investment in learning-by-using can contribute to the discovery of new uses for an existing product. Learningby-using entails a fixed-cost investment, but the resultant addition of approved drugs to the company's products can drive down unit cost through "economies of scope" in addition to economies of scale. Economies of scope occur when the firm's same fixed assets, both physical and human, can be deployed across a range of products, thus securing reductions in unit cost by the more complete utilization of those assets. The development of a new drug by a pharmaceutical company entails the fixed cost that is dedicated to that product, creating the need to achieve scale economies on the additional fixed cost. Thus, in the growth of the multi-product firm, unit-cost reductions are achieved by a combination of economies of scale and scope (Chandler, 2009, 1990; Teece, 1980).

\subsection{Organizational separation of drug pricing from drug demand}

In the presence of scale economies, the forces of supply and demand cannot set an equilibrium price for a drug (as is erroneously assumed by, for example, Krugman, 2018). Some form of strategic pricing needs to be implemented. ${ }^{4}$ Regulation by a national health scheme is one form of strategic pricing. As we explain below, the United States has strategic pricing for prescription medicines, but it is left under the control of business entities; specifically, pharmaceutical drug producers, health insurance companies, and pharmacy benefit managers. An understanding of the actual pricing decisions that emerge from their tripartite negotiations requires identification and rationalization of the strategies that each of these parties brings to the negotiations and how their ostensible inter-organizational differences concerning pricing are resolved.

The conditions of accessibility determine the number of people who have a medical need who can afford, usually with most of the price covered by health insurance, to buy a medicine to treat that need. Once these conditions are specified, a given population will generate a certain amount of what we term "accessible demand", which determines the potential for achieving economies of scale and scope, and hence for reducing the unit cost of a particular drug.

4 In the economics literature, this bureaucratic pricing has often been called "administered pricing" (Blair, 1959; Eichner, 2008; Means, 1972), but the term has been used with theoretical frameworks that are often inconsistent with PMI. We use the more general term "strategic pricing" to indicate that certain parties exercise control over pricing decisions for the sake of achieving their particular strategic objectives. 
Some medical needs, such as those for a rare disease that requires an "orphan drug", entail limited demand for a drug per unit of time, while other medical needs that are widespread, such as the treatment of depression, provide a mass market per unit of time. The qualifier "per unit of time" is important because if a drug is curative, the patients who, having taken the drug no longer have a medical need, will not be repeat customers. Since the firm's fixed-cost assets endure across units of time, the demand for non-curative drugs drives down unit cost by making greater use of the relevant assets over time. In the case of insulin for diabetes, for example, the medicine is noncurative, requiring regular treatments over the patient's lifetime. Given the same fixed cost and size of the patient population served, the unit cost of a curative medicine will be far higher than that of a non-curative medicine.

If a person with a medical need lacks insurance coverage or, with insurance, must incur high copays, deductibles, and premium increases, a higher drug price may make the medicine less affordable, and thus reduce accessible demand. If access to a medicine is a matter of life or death, however, people with a particular disease may die because they cannot afford the relevant medicine, and their deaths reduce the accessible demand for those medicines (Mazzucato and Roy, 2019). Thus, besides a humanitarian interest, drug companies may have an economic interest in product pricing that makes a medicine affordable to those in dire need of it.

A pharmaceutical company may be able to increase accessible demand by convincing patients or their doctors, who prescribe drugs, that they need the remedy that a medicine (purportedly) offers. The United States is one of the very few nations that permits the advertising of drugs. There have been numerous scandals related to the aggressive marketing of drugs to physicians. The ongoing opioid crisis in the United States unfortunately offers many examples of these, involving most notoriously Purdue Pharma, but also large manufacturers like Johnson \& Johnson, which Oklahoma lawyers recently ruled had "minimized the addictive painkillers' risks and promoted their benefits" in its years-long marketing campaign (Hotten, 2019). Drug companies contend that their marketing campaigns are providing information that makes people and their doctors aware of the existence, efficacy, and safety of a drug to meet their medical needs. For their part, drug companies can argue that the high cost of (necessary) marketing increases the fixed cost of accessing markets, and hence justifies higher drug prices.

Despite the fact that, with increases in accessible demand, the drug company could actually lower prices because of economies of scale and scope, the existing structure of unregulated pricing in the United States creates a marked bias toward increasing prices, and hence profits, even when economies of scale and scope have been achieved. Health-insurance companies and other intermediaries, which could negotiate in the interests of patients to drive down prices, can benefit from increases in the prices set by drug manufacturers. Rather than search for lower prices, intermediaries, including wholesale distributors and PBMs, derive profits from the value of list prices and thus benefit when it increases, and can therefore be considered as supply-side collaborators in their strategic pricing. The role of these intermediaries in strategic drug pricing in the United States will now be described.

Once a product receives market authorization, wholesale distributors (and sometimes other direct purchasers) buy the drug at the list price. This "wholesale acquisition cost" or WAC is the baseline price at which wholesale distributors (and sometimes other direct purchasers) acquire the drug, before discounts and rebates are applied based on market share, volume, and prompt payment (Kaiser Family Foundation, 2005, p. 17). They then store the medicines in warehouses and 
distribution centers across the country, from where they are delivered to pharmacies and hospitals. The amount which wholesale distributors receive for providing these logistics services is calculated as a percentage of the list price of the medicines they handle rather than the actual resources needed to distribute and store specific products. Thus, wholesale distributors stand to benefit from higher drug list prices (Cefalu et al., 2018, p. 7), particularly for medicines with high demand like insulin formulations.

Pharmacies and hospitals, which purchase drugs from wholesale distributors, dispense medicines to a patient once a prescription provided by a physician has been submitted. In the United States, physicians can have financial relationships with pharmaceutical companies, and analyses have indicated that there is an association between a physician receiving payments and their prescription of drugs from that manufacturer (recent studies include, for example, Fleischman et al., 2019, 2016; Sharma et al., 2018). The dispensary will then submit a bill to the individual's insurance plan, if they have one, and receive reimbursement for the prescription, plus fees for dispensing (Cefalo et al., 2018, p. 2). They may also collect a co-payment from the patient or, if a patient does not have health insurance that covers the prescription, the pharmacy will usually charge a price close to its purchase price, with a markup (ibid.).

These actors - the manufacturer, wholesale distributor, pharmacy and patient - represent the product flow of the pharmaceuticals supply chain, from production to storage, distribution, and dispensation. Beyond this chain, however, two further actors receive a share of the list price. These are PBMs and health insurers.

In theory, as noted, it is in the interest of insurers to seek lower list prices of medicines, where they cover the costs for patients. Historically, insurers' quest for lower list prices has also been the case in practice. As the list prices of many medicines have increased, however, insurance companies may have shifted the higher costs onto patients in the form of higher co-pays and premiums (Kaiser Family Foundation, 2019, pp. 156-158). Insurers often also receive rebates from drug manufacturers after the point of sale, incentivizing coverage of particular medicines and not others. In many parts of the United States, there is limited competition or no competition among health insurance companies, and so individuals cannot simply choose to leave their insurance plan if the cost of a drug borne by the customer increases. These monopolistic tendencies, combined with the possibility of deriving higher profits from list price increases, undermine the potential of insurance companies to negotiate on behalf of patients to drive down drug prices.

In the past, in the interest of their plans' patients, insurers were able to influence the list price of pharmaceutical products by way of PBMs. The first PBMs were established in the 1960s, with backing from business-sector insurance companies, which were increasingly tasked with managing small claims as business-sector prescription drug coverage grew (Strongin, 1999, pp. 23 ). In the decades since, however, their role has transformed dramatically. Since the 1980s, PBMs have assumed the role of fiscal intermediaries, using their relationships with insurers and the networks of pharmacies they had built to negotiate rebates with manufacturers based on the amount of their firm's products dispensed by the PBMs' participating pharmacies. They leverage their unique position as well to negotiate volume-pricing discounts with pharmacies, and create formularies, which are lists of preferred pharmaceutical products, incentivizing manufacturers to offer discounts to the PBMs on medicines that they want to be covered by insurers. 
The relationship that has developed between PBMs and pharmacies is perhaps the most important for understanding why PBMs stand to benefit from higher list prices rather than appease insurance plans by negotiating with manufacturers for upfront discounts. The fees charged to pharmacies by PBMs are based on list prices; PBMs thus have an interest in maintaining a high list price but negotiating retrospective rebates with the manufacturer, which they receive after the dispensation of the drug (Wapner, 2017). In most cases, these higher fees ultimately fall on individuals rather than insurance plans, as the insurers increase co-pays and premiums to cover the higher prices charged to pharmacies. PBMs have faced bipartisan criticism for this arrangement; in 2019, some US senators questioned the legitimacy of the power wielded by the three companies that dominate the PBM market and challenged the profits they make through high rebates (Kuchler, 2019).

The concentration of this activity and others in the pharmaceuticals supply chain is often cited as an important factor in the list-price increases of many drugs in the United States, and the consequences for reduced patient access (Sood et al., 2017). CVS Caremark (owned by CVS Health), Express Scripts (owned by Cigna), and OptumRx (owned by United Health) today manage about 70 percent of all prescription claims (Cefalu et al., 2018). Three wholesalers similarly control 85 percent of the market; five pharmacies hold 54 percent of their respective sector; and the market for insurers is increasingly concentrated (Sood et al., 2017).

The foregoing discussion reveals how the activities and interests of intermediary actors in the supply chain for medicines in the United States disadvantages patients in terms of their access to medicines and the prices that they pay. Although public health-insurance plans do have some discretion over the determination of drug prices, it is more accurate to describe the market for medicines in the United States as a supply-side oligopoly with negotiated strategic pricing involving producers, PBMs, and insurers. It is not the individual who decides whether to buy more or less of a drug at a different price; variations of quantity demanded with price are determined by negotiations between drug manufacturers and intermediaries, which in varying ways benefit from higher list prices.

\subsection{The theory of innovative enterprise and the case for drug-price regulation}

Given economies of scale and scope in drug supply and the need for strategic drug pricing, how should a drug be priced to promote outcomes that augment drug innovation, defined in terms of both technological improvement and patient access? In Figure 3, we have augmented Figure 2 by adding an assumed level of accessible demand $\left(\mathrm{ad}_{1}\right)$, without any assumption that those patients whose medical needs constitute that demand exert any influence on the product price. Recognizing that a business firm needs profit to survive and potentially grow through investment in capabilities, we can assume that the price should be set to at least unit cost, price ${ }_{\min }$, on the cost curve for the well-managed firm in Figure 2.

TIE, however, raises a number of reasons why a price that is higher than price min might be consistent with the pursuit of innovation objectives.

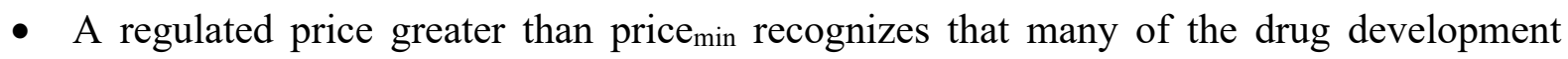
projects in which a pharmaceutical company invests will fail to yield safe and effective products that can be commercialized. Therefore, for the pharmaceutical firm, the profits 
from a successful drug will need to offset the losses from drug-development projects that fail.

- A portion of the firm's profits from a successful drug can be allocated to reward its employees in the form of secure employment and enhanced remuneration for contributing to the organizational-learning processes that generate a safer and more effective drug than had previously been available.

- A portion of profits retained within the firm can be allocated for investment in the next generation of the firm's innovative products.

Figure 3. The innovating firm's cost curve for a pharmaceutical drug, with given accessible demand

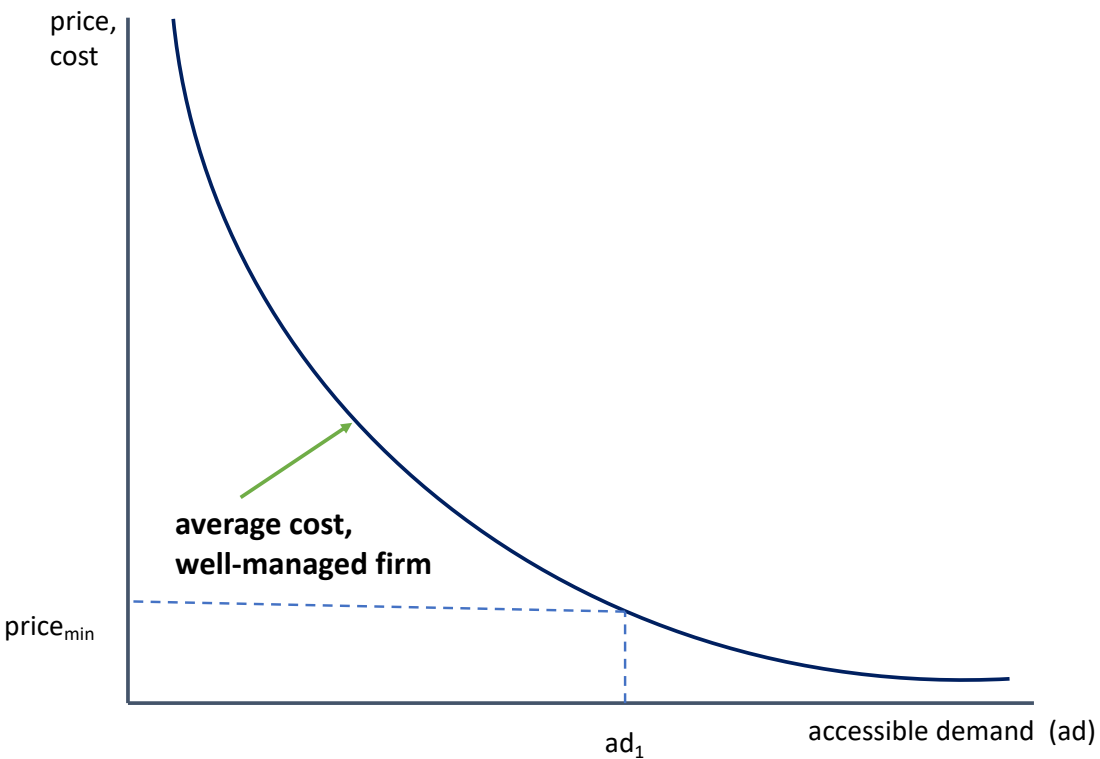

As stated at the outset of this paper, given the investment that the government and scientific community makes in the development of a drug that precedes and makes possible value-added by the pharmaceutical company that further develops, manufactures, and delivers the medicine, it only makes sense to recognize that the setting of the product price should not be left solely to the business firm that markets the drug.

Indeed, in the face of the uncertainty inherent in medical innovation, the government grants patents on medicines to encourage investment in the drug development process. What is the theory that says that the government should bestow a monopoly on a company but then take no responsibility for involvement in the price-setting process? Yet, in the United States, pharmaceutical companies reap all of the benefits from government investment in the knowledge base, government financial subsidies, and government grants of monopoly power, while being left to their own devices, in negotiation with insurers and PBMs, in setting product prices.

Product price affects the affordability of an approved drug, but it can also determine the amount of financial resources that a company controls for making new fixed-cost investment in the drug innovation process. That is because the prices of a company's existing products are prime 
determinants of a company's profits in any period. Corporate earnings retained out of profits provide the critical source of funding for a firm to make use of its existing productive capabilitiesincluding first and foremost the productive capabilities of its labor force, accumulated in previous drug-innovation processes - for investing in new drug projects. This ongoing process of using corporate retentions to build on a firm's existing productive capabilities drives the growth of the multiproduct enterprise (Lazonick, 2012, 2010).

We should not expect that the determinants of price ${ }_{\min }$, as depicted in Figure 3, are the same for all firms that compete in the same product market. It is inherent in any innovation process that no one knows at the outset the learning path that will be necessary to generate a higher-quality, lowercost product. Different firms concerned with the same disease make different decisions concerning the fixed-cost investments that must be made to develop, manufacture, and deliver a safe, effective, accessible, and affordable medicine for a particular indication.

In the United States, as noted above, existing government policy relevant to the pharmaceutical industry recognizes the critical importance of mitigating the uncertainty inherent in the drug innovation process through patents and market exclusivity (the key feature of the Orphan Drug Act of 1983). The purpose of this legislation is to incentivize a company to invest in the collective and cumulative learning that the drug innovation process requires. In addition, primarily through the NIH, the US government provides funding for the types of basic and applied research that underpin organizational learning by business firms (Lazonick and Tulum, 2011).

Beginning with the Bayh-Dole (or Patent and Trademark Law Amendments) Act of 1980, the US government has taken steps to ensure that business firms can gain access to knowledge created by federally funded research on highly advantageous terms. Bayh-Dole explicitly permits research institutes, including the nation's leading research universities, to transfer the results of federally funded research to commercial entities. The Stevenson-Wydler Technology Innovation Act of 1980 authorizes the establishment of Cooperative Research Centers (CRCs) to encourage industryuniversity collaboration and mandates that each federal laboratory establish an Office of Research and Technology Applications to actively engage in technology transfer from the labs to firms. The 1986 Federal Technology Transfer Act (FTTA) created the Cooperative Research and Development Agreement (CRADA) to foster government-business research collaboration, quicken technology transfer to business firms, and make it easier for firms to file patents based on this cooperative research, including military research. The National Technology Transfer and Advancement Act (NTTAA) of 1996 amended the Stevenson-Wydler Act to make it more attractive for drug companies to enter into CRADAs by placing a cap on the amount of royalties that federal researchers could receive on their inventions. Alongside the rights to intellectual property, university and government research labs provide pharmaceutical companies with experienced research personnel, many of whom, as discussed below, are granted potentially lucrative stock awards and stock options in venture-backed startups or in established pharmaceutical companies (Tulum and Lazonick, 2018).

However, as we discuss in detail in the next section of this paper, with all of this government support for the pharmaceutical drug industry, the US government imposes absolutely no regulations on how pharmaceutical companies make use of the financial resources that they control. A growing body of research shows that, because of the ways in which people in positions of strategic control in business corporations make use of the stock market, they can enrich themselves personally even as they undermine the social conditions of organizational integration 
and financial commitment that are critical to the drug-innovation process (Lazonick et al., 2017). The corporate-governance problem of the dominance of financialization over innovation functions differently for a young startup company that has done an initial public offering (IPO) of its shares on the stock market than it does for established companies that have grown large through a successful innovation in the past (Lazonick and Tulum, 2011; Montalban and Sakinç, 2013).

In the case of venture-backed startups, a listing on the NASDAQ stock exchange, which, because of lax listing requirements, a company can do without a record of profits or even a product, enables financiers, entrepreneurs, and directors to enrich themselves through the sale of company shares on the market. People in positions to exercise, or through their shareholding to influence, strategic control can use the stock market to bank tens, and in some cases hundreds, of millions of dollars for themselves even if the company never produces a commercial product. Although a listing on the stock exchange does permit a young company to sell treasury shares that can be used to finance the drug innovation process, the extent and persistence of this funding is dependent on a highly volatile stock market, and, as a result, is ill-suited for the financial commitment that, as TIE explains, is the social condition required to sustain the collective and cumulative learning processes that are critical to drug innovation.

Moreover, when a US pharmaceutical company is successful in drug innovation, those in positions of strategic control may use resultant profits, made greater by unregulated drug prices, to pump up the company's stock price, enriching themselves through their stock-based pay (Lazonick et al., 2017). As we document in the next section, established US pharmaceutical companies have increasingly turned from innovation to financialization by paying out massive distributions to shareholders in the form of cash dividends and stock buybacks, representing abuses of the resource-allocation power of those in positions of strategic control and undermining the social conditions of organizational integration and financial commitment. The broad implication of the financialization of strategic control in publicly listed pharmaceutical startups and going concerns is that, for the sake of the generation of safe, effective, accessible, and affordable medicines, public policy should regulate not only drug prices but also corporate resource allocation.

\section{Pricing for Medicine Innovation confronts arguments against drug-price regulation}

As stated at the outset, we identify four distinct, but not mutually exclusive, arguments that have been made for the status quo absence of regulation for drug pricing in the United States:

Argument 1. High drug prices are needed so that a pharmaceutical company has sufficient profits to fund future drug development.

Argument 2. Expectations of high corporate profits yielded by setting high drug prices incentivize financiers to make the risky investments needed for drug innovation.

Argument 3. New drugs save patients' lives and therefore provide value for money, even if they are expensive.

Argument 4. Other actors in the supply chain, and not the manufacturers, capture the higher profits from higher drug prices. 
In this section, we assess the validity of each of these arguments from the perspective of the TIE.

\subsection{Argument 1. High drug prices are needed so that a pharmaceutical company has sufficient profits to fund future drug development}

Pharmaceutical industry actors have long claimed that profits from the sale of drugs are reinvested in R\&D by the company that captures the profit. High drug prices are then justified by the company's declared anticipated R\&D costs to create a pipeline of new drugs under development. This argument has been made by the US pharmaceutical industry for decades. An article on price gouging by US drug companies in the Washington Post in 1985 stated: "Drug company executives added that prices have climbed recently to cover accelerated investment in researching and developing new and better medications to protect Americans." The article went on to say that, when, in a Congressional hearing, pharmaceutical executives were "asked for the percentage of consumer drug prices increases that is allotted to research and development, [they] could not produce a figure" (Horwitz, 1985). More recently, a 2017 report from Janssen Pharmaceutica summarized this argument in a discussion of its pricing approach, stating: "We have an obligation to ensure the sale of our medicines provides us with the resources necessary to invest in future research and development to address serious, unmet medical needs" (Janssen, 2017).

As we discuss in more detail shortly, the actual costs of drug development borne by drug manufacturers are disputed. There is no existing agreed upon methodology for estimating R\&D costs, and a company has an incentive to overstate the costs of new drug development in order to justify higher prices that it sets on its existing approved drugs. In setting the market prices of a company's drugs, a regulator implementing PMI would make its own informed assessment of the actual costs of the company's investment plans. The regulator would consider whether a) given the uncertainty of the drug development process, the company in question has accumulated the capabilities that increase the likelihood that it will succeed in its drug development plans; b) the list prices on its existing drugs that the company seeks to charge are warranted by the cost of its drug-development plans and do not hinder patient access to the drugs; and c) the company will actually use the higher profits realized from higher-priced existing drugs for investment in its planned drug innovation. The regulator would retain the power to claw back profits from past drug prices if the company does not subsequently follow through in making the R\&D investments that had justified the regulated prices of its existing drugs.

Evidence on US pharma from the past decades, in some cases going back to the mid-1980s, documents that higher list prices have been accompanied by increased shareholder-value extraction in the form of dividends and buybacks (Lazonick et al., 2017; Lazonick et al., 2019; Collington, 2020). There were 18 pharmaceutical companies among the 466 S\&P 500 companies in January 2019 that were publicly listed from 2009 to 2018. With combined profits of $\$ 588$ billion from 2009 through 2018, these 18 companies spent $\$ 335$ billion on buybacks and \$287 billion on dividends over that decade. These distributions to shareholders were 14 percent greater than the $\$ 544$ billion that these companies devoted to R\&D spending. The 18 pharmaceutical companies comprised 3.9 percent of the 466 companies from all industrial sectors, but they distributed 8.5 percent of all buybacks and 9.3 percent of all dividends. Buybacks and dividends amounted to 106 percent of the 18 companies' combined profits, compared with 92 percent for all 466 companies in the 2009-2018 sample (Lazonick et al., 2019). 
High drug prices, therefore, enabled big US pharmaceutical companies to increase distributions to shareholders; these elevated prices provided these companies with higher profits that could be used to pump up their stock prices and increase stock yields much more than to augment their R\&D expenditures. Indeed, over the decade 2009-2018, among the six largest US pharma companies by revenues, the proportions of profits allocated to distributions to shareholders were 95 percent at Johnson \& Johnson, 114 percent at Pfizer, 130 percent at Abbott/Abbvie, 151 percent at Merck, 93 percent at Eli Lilly, and 121 percent at Amgen.

In terms of specific medicines, analogue insulin products are a case in point. The list price of insulin had soared in the United States between 2008 and 2017. One study found that the list prices of seven analogue insulin medicines increased by 262 percent over these years (Hernandez et al., 2020). The net price (the amount that manufacturers received) increased by 51 percent in this period (ibid.). This increase in net price is reflected in revenue increases from insulin product lines at the three leading manufacturers, Novo Nordisk, Sanofi, and Eli Lilly, during this decade. Between 2010 and 2018, annual net revenue from insulin products across the three companies was on average $\$ 6.3$ billion (44 percent) higher than in 2009 . For all three companies, the United States constitutes a significant market for insulin products, with Novo Nordisk relying on it for almost half of its total sales revenue across all therapeutic lines.

Given that the insulin market in the United States is largely price inelastic, consisting of patients with type-1 and some with type- 2 diabetes, with no curative drug currently existing for type-1 diabetes, our earlier research sought to understand how the higher profits realized from these price increases had been allocated (Collington, 2020). During this period, all three companies distributed most of their profits to shareholders as dividends and buybacks. If funds had not been allocated to buybacks, Lilly and Sanofi could have each spent about 18 percent more on R\&D, while, just counting its external buybacks, Novo Nordisk could have spent 98 percent more. A summary of these data is presented in Table 1.

Table 1. Revenue, net income, and distributions to shareholders, major insulin manufacturers, 2009-2018

\begin{tabular}{|l|c|c|c|c|c|c|c|c|c|}
\hline COMPANY & iREV, \$b & tREV, \$b & NI, \$b & BB, \$b & DV, \$b & TSP, \$b & R\&D, \$b & $\begin{array}{c}\text { TSP/NI } \\
\%\end{array}$ & $\begin{array}{c}\text { R\&D/tREV } \\
\%\end{array}$ \\
\hline Eli Lilly & 39.6 & 223.1 & 33.1 & 9.0 & 21.7 & 29.1 & 50.4 & 88 & 23 \\
\hline Novo Nordisk & 91.5 & 142.8 & 42.9 & 21.5 & 18.8 & 40.3 & 18.8 & 94 & 13 \\
\hline \multicolumn{1}{|c|}{ of which external } &.. &.. &.. & 18.4 & 13.5 & 32.0 &.. & 75 &.. \\
\hline \multicolumn{1}{|c|}{ of which to Novo } &.. &.. &.. & 3.0 & 5.3 & 8.3 &.. & 19 &.. \\
\hline Sanofi & 66.9 & 418.4 & 64.0 & 11.4 & 41.1 & 52.5 & 61.7 & 82 & 15 \\
\hline
\end{tabular}

Notes: $\mathrm{iREV}=$ net revenue from insulin sales; $\mathrm{tREV}=$ total net revenue; $\mathrm{NI}=$ net income; $\mathrm{BB}=$ share

buybacks/repurchases; DV = cash dividends; TSP = total shareholder payout (share repurchases + cash dividends)

Source: Company Annual Reports

The distributions to shareholders at the three companies tracks the broader trend across the pharmaceutical industry of shareholder-value maximization over investment in R\&D, which undermines the development of safer, more effective drugs (see our discussion in section 2.2 of this paper). The increase in insulin list prices, which cannot be associated with an increase in the safety and efficacy of treatments - because it does not relate to increases in R\&D spending at the three companies - can be associated with a decrease in affordability and cost-related accessibility. Throughout the 2010s, patient organizations had reported numerous tragic cases of people with 
type-1 diabetes dying after attempting to ration their insulin prescriptions (T1 International, 2019). One academic study found that one in four of the diabetes patients surveyed experienced costrelated nonadherence to insulin medicines (Herkert et al., 2019), with wider evidence indicating that socioeconomic factors influence admissions for diabetic ketoacidosis (DKA) (Randall et al., 2011). The authors of the study concluded that it was likely that higher insulin prescription costs had serious consequences for diabetic patients. Thus, because higher insulin list prices can be associated with a decrease in accessibility and affordability while failing to improve drug safety and efficacy, it cannot be argued that higher list prices in this case were necessary for innovation. Indeed, a regulator implementing PMI would view the companies' corporate resource allocations of the past decade as undermining access to an innovative product.

\subsection{Argument 2. Expectations of high corporate profits yielded by setting high drug prices incentivize financiers to make the risky investments needed for drug innovation}

Many defenders of unregulated drug pricing in the United States not only overlook the role that government investment plays in the riskiest, most uncertain stages of drug innovation; they assume that it is venture capitalists that take on the greatest risk. This argument was recently made in a Forbes article, which contended that "a pharmaceutical industry without blockbuster pricing would not be viable, because it could not recover the cost of innovation" (Fleming, 2019):

Mega profits and dwindling productivity look bad to a public asked to pay high prices in the name of innovation. Yet those profits are what drive innovation throughout the industry, because they determine what pharma can pay to acquire a drug/company and provide the money. The purchase price is the private investors' return-on-investment. (ibid.)

Venture capitalists are incentivized to invest in startup biotech companies by expectations of returns through an IPO or sale of a venture-backed company to an established pharma company. In the case of an IPO, which are often product-less - and hence what Lazonick, Sakinç, and Tulum have dubbed "PLIPOs" - the gains to venture capitalists and other holders of private equity are typically based more on speculation than innovation (Lazonick and Sakinç, 2010; Lazonick and Tulum, 2011; for tracking of product development by PLIPOs, see McNamee et al., 2021). In the case of an acquisition deal with an established company, the price paid for the acquisition reflects the power of the acquiror to charge a high unregulated price if and when the acquisition results in an approved drug. Venture-capital investment depends largely on "news", such as that generated by clinical trials, as well as patent decisions. As Victor Roy notes, under this current model, patents are "not bargains between investors and the public for recouping the costs of research and development, but rather tied to the expectations of future value materialized in financial markets" (Roy, 2020; see also Roy, 2017).

A regulator enacting PMI would recognize that long-term, patient finance is necessary for the development of safer and more effective drugs. But while venture capital in theory could provide this financial commitment, in reality it has often proved disruptive of the collective and cumulative learning that is needed for successful drug development. The stock market speculation that creates opportunities for PLIPOs to issue public equity ebbs and flows, and at times even comes to a complete stop, as was the case in 2008-2010 when, owing to the financial crisis, there were 
virtually no biotech IPOs in the United States. In the process, employment in these companies is also volatile, and the learning that occurs is often neither collective nor cumulative.

\subsection{Argument 3. New drugs save patients' lives and therefore provides value for money, even if they are expensive}

In recent years, the concept of "value-based pricing" (VBP) has gained support across the political spectrum (Porter, 2010). In short, this approach suggests that the price of a drug should be based on the value derived by the patient and the potential for downstream cost-savings by the health system. The concept has spawned a number of proposals for reform to the current system in the United States, from calls for pricing to be related to Technology Appraisals, as exists in the United Kingdom, to "alternative payment mechanisms", including health care loans (HCLs) and drug mortgages. There are a few obvious moral questions that arise from the latter proposals, which Robin Feldman has detailed in a book on prescription drug pricing in the United States (Feldman, 2019). To illustrate: Parents of a child with type-1 diabetes no doubt value insulin far more than anything they own, because it keeps their child alive, but few people in the United States would believe it is just for a family to need to sell their home to gain access to a life-saving drug that was discovered almost a hundred years ago. In such situations, with the price set at what it costs not to die, if the unfortunate patient, their family, and/or the healthcare system can afford it, the price set by the marketer of the drug is simply "what society can bear" (Mazzucato and Roy, 2019, p. 105). Underpinning VBP, moreover, is the assumption that the company that controls the manufacture and marketing of a drug is its sole value creator (ibid.).

Note that the company that is authorized to sell the drug is not claiming that it needs the higher drug price to invest in future drug innovation (Argument 1., above) or to incentivize venture financing of drug innovation (Argument 2., above). It is simply arguing that because it holds the health of potential patients in its hands, it has the right to charge whatever the market will bear. Society can simply respond that if the company wants to have the right to sell the drug, then society has the right to set the price of the drug, given the monopoly position that the drug company holds. This societal right is consistent with the longstanding recognition that government agencies can and should intervene to set the product price of a "natural monopoly". Moreover, in the case of a pharmaceutical company, the monopoly is not "natural" (as was once deemed to be the case with electricity, gas, and telephone utilities) but rather is granted by society to the company in the form of a 20 -year drug patent.

The critique of VBP gains clarity from the TIE perspective: it is highly unlikely that the company that possesses the legal right to sell the drug developed the product all alone or all by itself. It is far from being the sole value creator. Innovation is collective and cumulative, so the beneficiaries of VBP, if it were to be applied, would not be the corporate entity which possesses the right to sell the drug but rather all of those parties whose skills, efforts, and finances went into developing the safe and effective product (Lazonick 2010; 2019). These parties would include large numbers of individuals who are and have been employees of the firm that aspires to engage in VBP as well as individuals who have worked, collectively and cumulatively, in developing the drug's knowledge base at many other business firms, government agencies, and civil-society organizations, often going back decades (see Hopkins and Lazonick, 2014; for a pharmaceutical case study, see Roy, 2017). 
Even more broadly, American households, which ultimately pay for prescription medicines, whether out-of-pocket or through insurance costs - or, perhaps more accurately, through the need to make career decisions based on the employer's insurance-provision guarantee-also have footed the bill of government-funded research at universities and other public institutions through taxation. The tens of thousands of people working in pharmaceutical research and developing new drugs have also often borne costs of their own higher educations at universities. These individuals are rarely motivated by the potential to become billionaires, but rather by the chance of a stable, well-remunerated, and intellectually challenging career, which may also improve health outcomes and enhance our collective scientific knowledge.

The proponents of VBP would quickly lose interest in the argument if they knew that the value of health benefits of the drug would be extracted by a myriad of participants, past and present, in the value-creation process. VBP is an argument for drug pricing that can only be made in a socioeconomic environment that has bought into the "maximizing shareholder value" (MSV) ideology that the only individuals who ever bore the risk of investing in a product are the shareholders of the company that controls the product. The MSV argument, put forth by academic economists known as agency theorists, is that, of all of a company's participants, it is only shareholders who allocate resources to the firm without a guaranteed return and, hence, it is only shareholders who have a claim on the firm's profits, if and when they occur (Lazonick and Shin, 2020).

In making this shareholder-primacy argument, however, agency theory lacks a theory of the firm that can explain how households as taxpayers (through government investment in physical infrastructure and human capabilities) and workers (through their valuing-creating employment) make productive contributions to the firm's profits without guaranteed returns. No matter the corporate tax rate, households as taxpayers face the risk that technological, market, and competitive uncertainties may prevent enterprises from generating profits and the related business tax revenues that serve as a return on government investments in infrastructure and capabilities. Moreover, corporate tax rates are politically determined. Households as taxpayers face the political uncertainty that, armed with MSV ideology, predatory value extractors may convince government policymakers that they will not be able to make value-creating investments unless the corporations are given tax cuts or financial subsidies that will permit higher after-tax profits.

Through their skills and efforts, workers regularly make productive contributions to the companies for which they work that are beyond the levels required to lay claim to their current pay. They do so, however, without guaranteed returns. An innovative company wants workers who apply their skills and efforts to organizational learning so that they can make productive contributions. For their part, workers expect that they will be able to build their careers with the company, putting themselves in positions to reap future benefits at work and in retirement. Yet these potential careers and returns are not guaranteed. In fact, under the "downsize-and-distribute" resource-allocation regime - entailing downsizing of the labor force and distribution of corporate cash to shareholders - that MSV ideology legitimizes, workers' careers and returns from them are generally undermined (Lazonick, 2015).

Therefore, workers supply their skills and efforts to innovation processes that could create value if successful, but they take the risk that their endeavors could be in vain. Far from reaping expected gains in the form of higher earnings and superior in-house career opportunity, workers could face cuts in pay and benefits, or even find themselves laid off, if the firm's innovative investment 
strategy fails. Even if the innovation process is successful, workers face the possibility that the institutional environment in which MSV prevails will empower corporate executives to cut some workers' wages and lay off other workers-and distribute the value that these employees helped to create as dividends and buybacks to shareholders.

MSV ideology ignores the risk-reward relation for households as taxpayers and workers in the operation and performance of business corporations (Lazonick and Mazzucato, 2013). The irony of MSV is that public shareholders typically never invest in the value-creating capabilities of the company at all (Lazonick, 2018). Rather, they purchase outstanding corporate equities with the expectation that dividend income (where applicable) will be forthcoming while they hold the shares. If and when they decide to sell the shares, they may be able to reap stock-price gains. As applied to pharmaceutical drug pricing in the United States, VBP is an argument for enriching a small number of value extractors at the financial, physical, and mental expense of the tens of millions of households for whom the economy should be run.

\subsection{Argument 4. Other actors in the supply chain, and not the manufacturers, actually capture the profits realized from higher drug prices}

Under the current US pharmaceuticals supply-chain structure, summarized in Figure 4 below, the delivery of a drug to patients is performed by companies other than the manufacturer. The value that these intermediaries extract is, as discussed in the introduction, related to the value of the list prices. PMI recognizes the importance of delivery in patient access to a drug; indeed, it holds that if patients cannot access new drugs, the pharmaceutical company that developed the drug cannot be said to be innovative. According to the PMI approach, however, the proportion of profits from the sale of a drug product to be distributed to intermediaries involved in the delivery must instead be determined on the basis of the value the intermediary function adds rather than the sectoral power of the intermediary group.

Figure 4. The pharmaceuticals supply chain in the United States

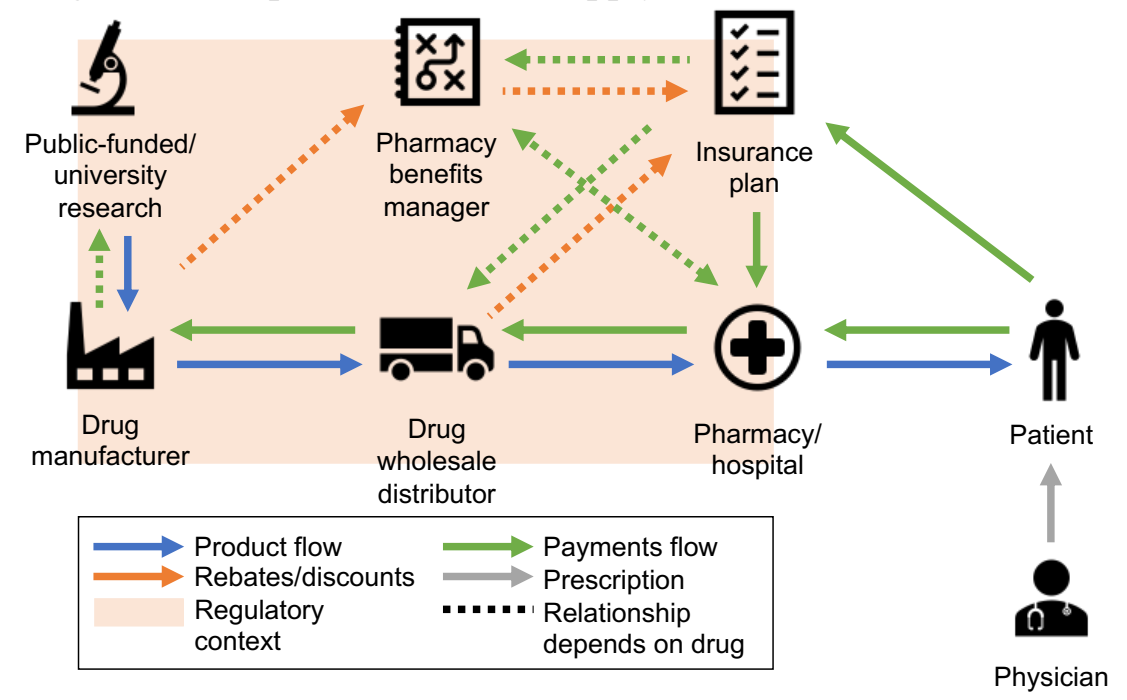

The argument that manufacturers do not benefit from the unregulated system that has seen the list prices of many products climb has gained prominence in the past decade as pharmaceutical companies have come under scrutiny for increasing the list prices of life-saving medicines. 
Industry representatives and academic researchers alike have argued, for example, that it is the monopolistic nature of firms in other subsectors involved in the pharmaceuticals supply chain that have accrued the gains from soaring insulin list prices (Cefalu et al., 2018; Tregoning, 2019). As previously stated, CVS Caremark, Express Scripts and OptumRx today manage about 70 percent of all prescription claims (Cefalu et al., 2018). Three wholesalers similarly control 85 percent of the market; five pharmacies hold 54 percent of their respective sector; and the market for insurers is also increasingly concentrated (Sood et al., 2017). Crucially, the profits of distributors, PBMs and pharmacies receive a rebate, discount, or fee based on the value of the list price.

It is certainly true that these intermediaries have profited from drug list-price increases (see Feldman, 2019). A study published in 2020 found that while the amount received by manufacturers for branded pharmaceutical products had increased by 60 percent between 2007 and 2018, list prices increased by 159 percent. The researchers highlighted that "although discounts partially offset list price increases...there was still a substantial increase in net prices over this period" (Hernandez et al., 2020). The difference, the authors concluded, was captured by actors including pharmacy benefits managers, pharmacies, and wholesale distributors.

Without changing the monopoly of supply created by the existing patent system, PMI seeks to ensure patient access and system affordability while incentivizing innovation by constraining how profits can be distributed and preventing extractive activity by shareholders and sharesellers. The preceding discussion suggests that a regulator enacting a pricing approach based on TIE would operate according to three "logics" of the innovative firm. It recognizes, firstly, that innovation is a collective, cumulative and uncertain process. Secondly, it recognizes that the ability to scale processes is a resource-efficiency driver. Thirdly, it recognizes that those firms that have accumulated capabilities through prior investments in innovation often possess superior capabilities for reinvesting in the next generation of innovative products, for which retained earnings provide the foundation of ongoing financial commitment.

\section{Regulatory capabilities for Pricing for Medicine Innovation}

In order to assess the potential for innovation in firms according to these logics, a regulator would require certain capabilities that are currently beyond the grasp of the FDA and other regulatory bodies in the United States. We define regulatory capabilities for PMI in terms of both human expertise and technical infrastructures. Specifically, the capabilities necessary to regulate the pharmaceutical industry according to this approach would require the development of professional knowledge and access to scientific and resource allocation (financial) data at the level of the specific drug (techno-scientific), the company developing it (firm-organizational), and wider micro- and meso- trends across the wider industry (sectoral).

The PMI regulator would need a deep understanding of the techno-scientific knowledge required for developing the drug in question, and of whether the company actually possesses or has the potential to develop these capabilities (Teece, 2016). To accumulate and sustain these capabilities, the regulator would need to recruit and train the professional base and develop technical information infrastructures necessary for evaluating pharmaceutical companies' capabilities and adapting to ecosystem changes. 
It also implies that the prospective costs of drug development are known to the PMI regulator, and therefore that $\mathrm{R} \& \mathrm{D}$ cost projections are transparent and based on an agreed-upon methodology. At present, there is a lack of reliable data on R\&D costs (Colbert et al., 2020). Since the 1980s, the pharmaceutical industry-funded Tufts Center for Drug Development has published estimates of the costs of bringing a drug to market. However, these studies have been challenged on a number of grounds (DiMasi et al., 2016, 1991; DiMasi and Paquette, 2004). Firstly, they are not replicable, as they rely on data provided by companies to the Center. A pharmaceuticals regulator must function as a trusted civil servant who has access to proprietary data on the costs of drug development that can be used for price regulation. The regulator must have the competences, as well as the mandate, to assess the accuracy of these data, and in particular to discern whether the drug company is seeking to inflate the actual costs of drug development, manufacture, and delivery to secure a higher regulated price than is warranted.

The Tufts studies have also been challenged for including "opportunity costs"-projections of what the company could have done with its money had it not engaged in research (Feldman, 2019). An opportunity cost is relevant for evaluating alternative portfolio investments, comparing the risk-reward relation for the allocation of a portfolio fund across available business and government securities traded on the market. But opportunity cost is not useful as a component of cost when considering direct investments in innovative products that do not yet exist. From the TIE perspective, it is the uncertainty of drug innovation that imposes a cost on a drug company because it must make investments with the expectation that a proportion of the projects will fail to generate a commercial product. Even in a well-managed pharmaceutical company, a reasonable calculation of the cost of product failure due to uncertainty may actually exceed an "opportunity cost" level as a cost component of those products that are successful. At the same time, however, a focus on the uncertainty of drug innovation raises the question of how diversified or specialized a wellmanaged drug company should be to mitigate the risk of project failure.

A final issue with the Tufts Center for Drug Development studies, as well as a number of other $R \& D$ cost-estimate studies, is that they are based on aggregate data that do not take into account the variability of R\&D cost for different types of drugs. Greater transparency about the cost of $\mathrm{R} \& \mathrm{D}$ resource allocation for specific drugs would enable a regulator to develop cost estimates for future R\&D within companies based on the specificities of the biotechnologies and infrastructures needed. Access to accurate and transparent information about how a company distributes its sales revenue would also enable the PMI regulator to assess the innovative capabilities of the firm-i.e., whether profits are used to augment R\&D or are extracted for non-innovative purposes. As we have seen, the currently available evidence shows that major US companies have not been investing the higher profits realized from drug-price increases in the drug innovation process. Rather, they have been using these profits to increase stock yields (Lazonick et al., 2019).

In addition to the scientific expertise necessary to estimate R\&D cost within companies, and the organizational knowledge to assess innovative capabilities of a firm based on its resource allocation decisions, to implement PMI, a regulator would need access to details of governmental contributions to the drug's development and the ability to analyze this historic data (see Roy, 2017). Researchers at Bentley University's Center for the Integration of Science and Industry have developed methods for gauging how earlier investments in research on biological targets contributed to a drug's development. One of their studies shows that "NIH funding contributed to every one of the [210] NMEs [new molecular entities] approved from 2010-2016 and was focused primarily on the drug targets rather than on the NMEs themselves" (Cleary et al., 2018). The 
findings from research conducted by the Center have empirically challenged the idea that pharmaceutical firms are the most significant investors in drug development. With its recognition that drug development is a cumulative process, the ability to estimate the contributions of earlier research institutions, business firms and government agencies to the learning processes that enable a drug to gain approval will improve the regulator's estimation of the actual contribution of the company in question to the drug's development, and thereby ascertain an appropriate price for the product.

The logics and capabilities derived from TIE that we have described in the preceding two sections support the development of safer, more effective drugs that become more accessible and more affordable to patients within pooled purchasing systems, such as health insurance, because they recognize both the learning costs that are the essence of innovation and the economies of scale that can transform an expensive learning process into an affordable product.

\section{Conclusion: Implementing Pricing for Medicine Innovation}

The discussions in this paper have drawn on the theory of innovative enterprise and existing empirical data on pharmaceutical company cash flows to propose a new approach to drug pricing that seeks to determine medicine list prices on the basis of actual firm-level investment in innovative capabilities as well as the accessibility and affordability of innovative products to patients.

TIE provides a framework for understanding a pharmaceutical company's conditions of supply and demand in drug pricing, recognizing the centrality of collective and cumulative investments by government agencies and businesses in the capabilities that underpin the drug development process. Regulation to support pharmaceutical innovation should aim to foster strategic control, organizational integration, and financial commitment in order to overcome the challenges inherent in the innovation process - namely, that it is uncertain, collective, and cumulative. PMI does not call for an end to monopoly power, although there may be a need to reform the existing patent system (Feldman 2012; Feldman and Frondorf, 2017). PMI recognizes that a degree of monopoly power may be required to incentivize drug development and achieve economies of scale. There is a need to ensure that those firms that enjoy patent rights possess the capabilities to invest in the drug innovation that the patents are meant to protect. Assuming that alignment between market power and productive power, PMI seeks to regulate the amount of corporate profits available to the firm and their allocation to drug innovation.

Using TIE, in Section 3, we provide a critique of four distinct arguments that have been frequently invoked in contemporary drug pricing debates. We show that although drug development costs are indeed high, the evidence suggests that investment in $R \& D$ has in fact been increasingly marginalized by distributions to shareholders and sharesellers. Thus, list price increases cannot be said to be required to augment innovative capabilities or reward past investments.

We tackle arguments for value-based pricing, which in practice have engendered a wide range of proposals for reform. VBP makes the untenable assumption that the company that has the right to sell a drug has the right to charge whatever the market will bear for that drug. Besides being morally reprehensible, this argument is economically nonsensical. As we have argued, with its roots in the flawed ideology that a company should be run to maximize shareholder value, VBP 
ignores the contributions to drug innovation of collective and cumulative learning prior to and beyond that undertaken by the particular pharma company that manufactures and markets the drug. Indeed, if the firm that engages in VBP uses the resultant profits to increase distributions to shareholders and sharesellers, it may even deny its own employees shares in the value that they helped to create. These employees can be rewarded by allocating a portion of profits to higher pay, more secure employment, and superior career opportunity.

At the same time, it must be recognized that in the United States, the absence of drug price regulation means that the pharmaceutical companies, PBMs, and health insurers that - through their own internal negotiations - set drug prices are imposing their own notions of "value" on society, including their intellectual-property right to charge prices that they think the society can bear. It is not "the market" that is setting these high prices, as those who exercise that pricing power would like the public to believe. Even though drug prices are not regulated in the United States, they are negotiated-but without the public having a seat at the bargaining table. The creation of a PMI regulator would not only provide the public a seat at the table; given the public character of pharmaceuticals, the PMI regulator would provide the public with a democratically accountable body that sets up the table and decides on the basis of a consistent set of principles which industry actors should have seats at it. Representatives appointed by the PMI regulator who sit at the table, would be equipped with a coherent theory of drug pricing for the sake of innovative medicines and the body of contextual knowledge needed to implement TIE's logic for the specific drug being priced.

While patient finance is critical for drug development, expectations that high corporate profits will be distributed to shareholders and sharesellers foment financial speculation and encourage stockprice manipulation, while undermining the collective and cumulative learning needed for successful innovation. We do not dispute that there are other actors in the supply chain who may have a claim on a share of profits realized from higher drug prices, but we reject the suggestion that the power of intermediary actors should drive list prices. A PMI regulator would seek to ensure that the proportion of profits from the sale of a drug product distributed to intermediaries be determined on the basis of the value the intermediary function adds rather than the sectoral power of the intermediary group.

In the final section of the paper, we have outlined the capabilities that a regulator responsible for determining an appropriate price according to PMI would need to possess. For various reasons, many of these are currently beyond the grasp of the FDA and other regulatory bodies in the United States. We recognize that, even with the passage of legislation that sanctions the PMI approach, the development of the capabilities of PMI regulators would require significant investment in education and training. We nonetheless maintain that these regulatory capabilities are critical if a nation wants to have a pharmaceutical industry in the business sector that is innovative and delivers value for patients while recognizing the contributions of government and the wider society to the value-creation process.

In September 2021, the Department of Health and Human Services (HHS) published its Comprehensive Plan for Addressing High Drug Prices, in response to President Biden's Executive Order 14036, "Promoting Competition in the American Economy" (US Department of Health and Human Services, 2021). The report proposes a number of policies, including increasing data collection from PBMs to improve transparency about prices, rebates, and out-of-pocket spending on prescription medications, and mandating drug price negotiation in Medicare Parts B and D on 
similar terms as exist for the Veterans' Health Administration. It also recommends legislation to cap prices for some areas of the administration and to limit the extent to which a company can increase the list price of a drug within a short period of time.

The "Comprehensive Plan" does not, however, provide an approach, such as PMI, that would enable the government as regulator to set drug prices designed to support medicine innovationthe development, manufacture, and delivery of safe, effective, accessible, and affordable drugs. Notwithstanding President Joe Biden's recognition that stock buybacks undermine innovation more generally (Biden, 2016), the HHS plan does not even raise the question of the egregious distributions of corporate cash by pharmaceutical companies to shareholders.

What we have identified as corporate financialization does, however, receive considerable attention in a December 2021 report, Drug Pricing Investigation, issued by the majority staff of the US House of Representatives Committee on Oversight and Reform (2021b). The report argues that executive compensation at Big Pharma companies has created incentives for unwarranted price increases, and it also contends that "even if the pharmaceutical industry collected less revenue due to pricing reforms, drug companies could maintain or even exceed their current R\&D expenditures if they reduced spending on stock buybacks and dividends" (ibid., p. xvi; see also US House of Representatives Committee on Oversight and Reform, 2021b). But the Committee's Drug Pricing Investigation makes no reference to academic studies on these issues (including our own), and its policy recommendations make no attempt to address the implications of corporate financialization for drug-price regulation, confining itself to calls for reforms that address anticompetitive practices and greater transparency from pharmaceutical companies concerning their investment costs.

Our findings indicate that price caps and increased transparency to constrain price increases are unlikely to augment innovation in a system that is oriented towards shareholder-value maximization, even if they improve affordability. Many others have also proposed price constraining legislation to improve patient access or balance what is perceived as "fair" for patients versus manufacturers (for recent proposals, see, for example, Moon et al., 2020; Raimond et al., 2021). Any argument for drug pricing that can benefit patients must recognize the collective, cumulative, and uncertain character of the innovation process as well as the problem of corporate financialization when profits from high drug prices are used for cash distributions to shareholders and sharesellers rather than for investment in the pharmaceutical firm's innovative capabilities. If implemented properly, with the theory of innovative enterprise as its guide, PMI could both improve the affordability of medicines and enhance the innovative performance of pharmaceutical companies. 


\section{References}

American Medical Association, 2021. Competition in Health Insurance: A Compehrensive Study of U.S. Markets. American Medical Association.

Biden, J. 2016, "How short-termism zaps the economy," Wall Street Journal, September 27, https://www.wsj.com/articles/how-short-termism-saps-the-economy-1475018087.

Blair, J.M., 1959. "Administered Pricing: A Phenomenon in Search of a Theory," American Economic Review, 49, 2: 431-450.

Cefalu, W.T., Dawes, D.E., Gavlak, G., Goldman, D., Herman, W.H., Nuys, K.V., Powers, A.C., Taylor, S.I., Yatvin, A.L., 2018. "Insulin Access and Affordability Working Group: Conclusions and Recommendations," Diabetes Care, 41, 6: 1299-1311, https://doi.org/10.2337/dci18-0019

Chandler, A.D., 2009. Shaping the Industrial Century: The Remarkable Story of the Evolution of the Modern Chemical and Pharmaceutical Industries. Harvard University Press.

Chandler, A.D., 1990. Scale and Scope: The Dynamics of Industrial Capitalism. Harvard University Press.

Cleary, E.G., Beierlein, J.M., Khanuja, N.S., McNamee, L.M., Ledley, F.D., 2018. "Contribution of NIH Funding to New Drug Approvals 2010-2016," PNAS 115, 10: 2329-2334.

https://doi.org/10.1073/pnas.1715368115

Cleary, E.G., Jackson, M., Acevedo, A., Ledley, F.D., 2020. "Characterizing the Public Sector Contribution to Drug Discovery and Development: the Role of Government as a First Investor," Institute for New Economic Thinking, https://www.ineteconomics.org/uploads/papers/Publicsector-contribution-to-drug-discovery-and-development.pdf

Cohen, R.A., Zammitti, E.P., Martinez, M.E., 2018. "Health Insurance Coverage: Early Release of Estimates From the National Health Interview Survey, 2017," National Center for Health Statistics, https://www.cdc.gov/nchs/data/nhis/earlyrelease/insur201805.pdf.

Cohen, W.M., Levinthal, D.A., 1990. "Absorptive Capacity: A New Perspective on Learning and Innovation," Administrative Science Quarterly, 35, 1: 128-152. https://doi.org/10.2307/2393553

Colbert, A., Rintoul, A., Simão, M., Hill, S., Swaminathan, S., 2020. "Can Affordability and Innovation Coexist for Medicines?" BMJ 368, https://doi.org/10.1136/bmj.17058

Collington, R., 2020. "Profits, Innovation and Financialization in the Insulin Industry," Institute for New Economic Thinking Working Paper No. 120. https://doi.org/10.36687/inetwp120

DiMasi, J.A., Paquette, C., 2004. "The Economics of Follow-on Drug Research and Development: Trends in Entry Rates and the Timing of Development," Pharmacoeconomics 22, 2:1-14. https://doi.org/10.2165/00019053-200422002-00002

DiMasi, J.A., Grabowski, H.G., Hansen, R.W., 2016. Innovation in the pharmaceutical industry: New estimates of R\&D costs. J Health Econ 47, 20-33.

https://doi.org/10.1016/j.jhealeco.2016.01.012

DiMasi, J.A., Hansen, R.W., Grabowski, H.G., Lasagna, L., 1991. "Cost of Innovation in the Pharmaceutical Industry," Journal of Health Economics, 10, 2: 107-142.

https://doi.org/10.1016/0167-6296(91)90001-4

Eichner, A.S., 2008. The Megacorp and Oligopoly: Micro Foundations of Macro Dynamics, Reissue edition. Cambridge University Press. 
Fein, A.J., 2021. "The top pharmacy benefit managers of 2020: Vertical integration drives consolidation," Drug Channels, April 6, https://www.drugchannels.net/2021/04/the-toppharmacy-benefit-managers-pbms.html.

Feldman, R., 2012, Rethinking Patent Law, Harvard University Press.

Feldman, R., 2019. Drugs, Money, and Secret Handshakes: The Unstoppable Growth of Prescription Drug Prices. Cambridge University Press.

Feldman R., Frondorf, E., 2017, Drug Wars: How Big Pharma Raises Prices aand Keeps Generics Off the Market, Cambridge University Press.

Fleischman, W., Agrawal, S., King, M., Venkatesh, A.K., Krumholz, H.M., McKee, D., Brown, D., Ross, J.S., 2016. "Association Between Payments from Manufacturers of Pharmaceuticals to Physicians and Regional Prescribing: Cross Sectional Ecological Study," BMJ, 354, i4189. https://doi.org/10.1136/bmj.i4189

Fleischman, W., Agrawal, S., Gross, C.P., Ross, J.S., 2019. "Association of Pharmaceutical Manufacturer Payments to Physicians and Prescribing Dosage of Opioids," Journal of General Internal Medicine, 34, 7: 1074-1076. https://doi.org/10.1007/s1 1606-019-04897-9

Fleming, S., 2019. "Drug prices and innovation," Forbes, June 20, https:/www.forbes.com/sites/stanfleming/2019/06/20/the-relationship-between-drug-prices-andinnovation/?sh=3a119fae4b11

Frakt, A., 2021. "Drug prices by committee: One way Biden could lower costs," New York Times, February 11, https://www.nytimes.com/2021/02/11/upshot/biden-drug-prices.html

Fried, M., 2018. "Prescription for Poverty: Drug companies as tax dodgers, price gougers, and influence peddlers," Oxfam International, September 17, https://doi.org/10.1163/22107975_HRD-9824-20180019

Herkert, D., Vijayakumar, P., Luo, J., Schwartz, J.I., Rabin, T.L., DeFilippo, E., Lipska, K.J., 2019. "Cost-Related Insulin Underuse Among Patients With Diabetes," JAMA Internal Medicine, 179, 1: 112-114. https://doi.org/10.1001/jamainternmed.2018.5008

Hernandez, I., San-Juan-Rodriguez, A., Good, C.B., Gellad, W.F., 2020. "Changes in List Prices, Net Prices, and Discounts for Branded Drugs in the US, 2007-2018." JAMA, 323, 9: 854-862. https://doi.org/10.1001/jama.2020.1012

Hopkins, M., Lazonick, W., 2014. "Who Invests in the High-Tech Knowledge Base?" Institute for New Economic Thinking Working Paper Series No. 14, https://www.ineteconomics.org/uploads/papers/WP14-HopkinsLazonick.pdf

Hopkins, M., Lazonick, W., 2016. "The Mismeasure of Mammon: Uses and Abuses of Executive Pay Data," Institute for New Economic Thinking Working Paper No. 49, https://www.ineteconomics.org/research/research-papers/the-mismeasure-of-mammon-uses-andabuses-of-executive-pay-data

Horwitz, S., 1985. "Drug industry accused of gouging public," Washington Post, July 16, https://www.washingtonpost.com/archive/business/1985/07/16/drug-industry-accused-ofgouging-public/b5dd1e8d-ac13-4860-9fd8-e297c546f11b/

Hotten, R., 2019. "Opioid crisis: Johnson \& Johnson hit by landmark ruling," BBC News, August 27, https://www.bbc.com/news/business-49452373 
Hughes, S.S., 2011. Genentech: The Beginnings of Biotech. University Of Chicago Press, Chicago.

Janssen, 2017. "2017 Janssen U.S. Transparency Report," https://transparencyreport.janssen.com/_document/2017-janssen-us-transparency-reportexecutive-summary?id $=00000178-7175$-da47-a57c-7df526720000

Kaiser Family Foundation, 2005. "Follow the Pill: Understanding the U.S. Commercial Pharmaceutical Supply Chain," February 28, https://www.kff.org/other/report/follow-the-pillunderstanding-the-u-s/

Kaiser Family Foundation, 2019. "2019 Employer Health Benefits Survey," September 25, https://www.kff.org/health-costs/report/2019-employer-health-benefits-survey/

Kaiser Family Foundation, 2022. "Status of State Medicaid Expansion Decisions: Interactive Map," January 18, https://www.kff.org/medicaid/issue-brief/status-of-state-medicaid-expansiondecisions-interactive-map/.

Keiser-Starkey, K., Bunch, L.N., 2020. "Health Insurance Coverage in the United States: 2019," Current Population Reports. United States Census Bureau, September 15, https://www.census.gov/library/publications/2020/demo/p60-271.html

Kennedy, J., Morgan, S., 2006. "A Cross-national Study of Prescription Nonadherence Due to Cost: Data from the Joint Canada-United States Survey of Health." Clinical Therapeutics, 28, 8: 1217-1224. https://doi.org/10.1016/j.clinthera.2006.07.009

Krugman, P., 2018. "What's good for pharma isn't good for America (wonkish)," New York Times, May 12, https://www.nytimes.com/2018/05/12/opinion/whats-good-for-pharma-isntgood-for-america-wonkish.html

Kuchler, H., 2019. "Pharmacy benefit managers face bipartisan criticism," Financial Times, April 9, https://www.ft.com/content/a65d6fcc-5ade-11e9-939a-341f5ada9d40.

Lazonick, W., 2009. Sustainable Prosperity in the New Economy? Business Organization and High-Tech Employment in the United States, W.E. Upjohn Institute for Employment Research.

Lazonick, W., 2010. "The Chandlerian Corporation and the Theory of Innovative Enterprise," Industrial and Corporate Change, 19, 2: 317-349, https://doi.org/10.1093/icc/dtq005.

Lazonick, W., 2012. "The Theory of Innovative Enterprise: Methodology, Ideology, and Institutions," in Moudud, J.K., Bina, C., Mason, P.L. (eds.), Alternative Theories of Competition: Challenges to the Orthodoxy. Routledge: 127-159.

Lazonick, W., 2015. "Stock Buybacks: From Retain-and Reinvest to Downsize-and-Distribute," Center for Effective Public Management, Brookings Institution., April 17, https://www.brookings.edu/research/stock-buybacks-from-retain-and-reinvest-to-downsize-anddistribute/.

Lazonick, W., 2018. "The Functions of the Stock Market and the Fallacies of Shareholder Value," in Driver, C., Thompson, G. (eds.), What Next for Corporate Governance? Oxford University Press: 117-151.

Lazonick, W., 2019. "The Theory of Innovative Enterprise," in Clarke, T., O'Brien, J., O'Kelley, C.R.T. (eds.), The Oxford Handbook of the Corporation, Oxford University Press: 490-514, https://doi.org/10.1093/oxfordhb/9780198737063.013.12 
Lazonick, W., 2022. "Is the Most Unproductive Firm the Foundation of the Most Efficient Economy? Penrosian Learning Confronts the Neoclassical Fallacy." International Review of Applied Economics, forthcoming.

Lazonick, W., Mazzucato, M., 2013. The Risk-Reward Nexus in the Innovation-Inequality Relationship: Who Takes the Risks? Who Gets the Rewards?" Industrial and Corporate Change, 22, 4: 1093-1128, https://doi.org/10.1093/icc/dtt019

Lazonick, W., O’Sullivan, M., 2000. "Maximizing Shareholder Value: A New Ideology for Corporate Governance," Economy and Society, 29, 1: 13-35. https://doi.org/10.1080/030851400360541

Lazonick, W., Sakinç, E., 2010. "Do Financial Markets Support Innovation or Inequity in the Biotech Drug Development Process?" Paper presented at the Workshop on Innovation and Inequality: Pharma and Beyond, Scuola Superiore Sant'Anna, Pisa, Italy, May 15-16.

Lazonick, W., Shin, J.-S., 2020. Predatory Value Extraction: How the Looting of the Business Enterprise Became the US Norm and How Sustainable Prosperity Can Be Restored. Oxford University Press.

Lazonick, W., Tulum, Ö., 2011. "US Biopharmaceutical Finance and the Sustainability of the Biotech Business Model," Research Policy 40, 9: 1170-1187.

https://doi.org/10.1016/j.respol.2011.05.021

Lazonick, W., Tulum, Ö., 2015. "Global Tax Dodging Just One Part of Pfizer's Corrupt Business Model," Institute for New Economic Thinking, December 3, https://www.ineteconomics.org/perspectives/blog/global-tax-dodging-just-one-part-of-pfizerscorrupt-business-model.

Lazonick, W., Moss, P., Salzman, H., Tulum, Ö., 2014. "Skill Development and Sustainable Prosperity: Cumulative and Collective Careers versus Skill-Biased Technical Change." Institute for New Economic Thinking Working Group on the Political Economy of Distribution Working Paper No. 7, December, https://www.ineteconomics.org/research/research-papers/skilldevelopment-and-sustainable-prosperity-cumulative-and-collective-careers-versus-skill-biasedtechnical-change.

Lazonick, W., Hopkins, M., Jacobson, K., Sakinç, M.E., Tulum, Ö., 2017. "US Pharma's Business Model: Why It is Broken, and How It Can Be Fixed," in Tyfield, D., Lave, R., Randalls, S., Thorpe, C. (eds.), The Routledge Handbook of the Political Economy of Science. Routledge: 83-100.

Lazonick, W., Tulum, Ö., Hopkins, M., Sakinç, M.E., Jacobsen, K., 2019. "Financialization of the U.S. Pharmaceutical Industry," Institute for New Economic Thinking, December 2, https://www.ineteconomics.org/perspectives/blog/financialization-us-pharma-industry.

Mazzucato, M., Roy, V., 2019. "Rethinking Value in Health Innovation: From Mystifications towards Prescriptions," Journal of Economic Policy Reform, 22, 2: 101-119.

https://doi.org/10.1080/17487870.2018.1509712.

McNamee, L. M., Cleary, E. G., Zhang, S., Salim, U., and Ledley, F. D., 2021, "Late-stage Product Development and Approvals by Biotechnology Companies after Initial Public Offering, 1997-2016," Clinical Therapeutics, 43, 1: 156-171. 
Means, G.C., 1972. "The Administered-Price Thesis Reconfirmed," American Economic Review 62, 3: 292-306.

Mikulic, M., 2021. "U.S. pharmaceutical industry," Statista, September 24, https:/www.statista.com/topics/1719/pharmaceutical-industry/\#dossierKeyfigures.

Montalban, M., Sakinç, M.E., 2013. "Financialization and Productive Models in the Pharmaceutical Industry," Industrial and Corporate Change, 22, 4: 981-1030.

https://doi.org/10.1093/icc/dtt023

Moon, S., Mariat, S., Kamae, I., Pedersen, H.B., 2020. "Defining the Concept of Fair Pricing for Medicines," BMJ, 368. https://doi.org/10.1136/bmj.14726.

National Center for Health Statistics, 2019. "Health, United States: 2018," US Department of Health and Human Services, https://www.cdc.gov/nchs/data/hus/hus18.pdf.

National Institutes of Health, 2022. "Office of Budget,"

https://officeofbudget.od.nih.gov/index.htm.

National Science Board, 2020. "The State of U.S. Science and Engineering 2020," National Science Foundation, https://ncses.nsf.gov/pubs/nsb20201.

Porter, M.E., 2010. "What is Value in Health Care?" New England Journal of Medicine. 363, 26: 2477-2481.

Raimond, V.C., Feldman, W.B., Rome, B.N., Kesselheim, A.S., 2021. "Why France Spends Less than the United States on Drugs: A Comparative Study of Drug Pricing and Pricing Regulation," The Milbank Quarterly, 99, 1: 240-272, https://doi.org/10.1111/1468-0009.12507

Randall, L., Begovic, J., Hudson, M., Smiley, D., Peng, L., Pitre, N., Umpierrez, D., Umpierrez, G., 2011. "Recurrent Diabetic Ketoacidosis in Inner-city Minority Patients: Behavioral,

Socioeconomic, and Psychosocial Factors," Diabetes Care, 34, 9: 1891-1896, https://doi.org/10.2337/dc11-0701

Roy, V., 2017, The Financialization of a Cure: The Political Economy of Biomedical Innovation, Product Pricing, and Public Health, PhD dissertation, University of Cambridge, June, https://www.repository.cam.ac.uk/handle/1810/267738.

Roy, V., 2020. "A Crisis for Cures? Tracing Assetization and Value in Biomedical Innovation," in Birch, K., Muniesa, F. (eds.), Assetization: Turning Things into Assets in Technoscientific Capitalism. MIT Press: 97-124.

Sharma, M., Vadhariya, A., Johnson, M.L., Marcum, Z.A., Holmes, H.M., 2018. "Association between Industry Payments and Prescribing Costly Medications: An Observational Study Using Open Payments and Medicare Part D Data," BMC Health Services Research, 18, 1: 236, https://doi.org/10.1186/s12913-018-3043-8

Sood, N., Shih, T., Van Nuys, K., Goldman, D., 2017. "The Flow of Money Through the Pharmaceutical Distribution System," USC Schaeffer Center, June 6, https:/healthpolicy.usc.edu/research/flow-of-money-through-the-pharmaceutical-distributionsystem/.

Strongin, R.J., 1999. "The ABCs of PBMs," National Health Policy Forum, October 27, https://hsrc.himmelfarb.gwu.edu/sphhs_centers_nhpf/40/, 
T1International, 2019. "Costs and Rationing of Insulin and Diabetes Supplies: Findings from the 2018 T1 International Patient Survey," https:/www.tlinternational.com/media/assets/file/T1International_Report__Costs_and_Rationing_of_Insulin_Diabetes_Supplies_2.pdf.

Teece, D.J., 1980. "Economies of Scope and the Scope of the Enterprise," Journal of Economic Behavior \& Organization 1, 3: 223-247, https://doi.org/10.1016/0167-2681(80)90002-5.

Teece, D.J., 2016. "Dynamic Capabilities and Entrepreneurial Management in Large Organizations: Toward a Theory of the (Entrepreneurial) Firm," European Economic Review, 86: 202-216, https://doi.org/10.1016/j.euroecorev.2015.11.006

Tikkanen, R., Osborn, R., Mossialos, E., Djordevic, A., Wharton, G.A., 2020. "International Health Care System Profiles: United States." The Commonwealth Fund, June 5, https://www.commonwealthfund.org/international-health-policy-center/countries/united-states.

Tolbert, J., Orgera, K., Singer, N. 2019. "Key Facts about the Uninsured Population," The Henry J. Kaiser Family Foundation, December, hhttps://files.kff.org/attachment//fact-sheet-key-factsabout-the-uninsured-population.

Tregoning, K.W., 2019. "Testimony of Kathleen W. Tregoning, Executive Vice President, External Affairs, Sanofi, Before the House Energy and Commerce Subcommittee on Oversight and Investigations," US House of Representatives, April 10, https:/www.aljazeera.com/mritems/Documents/2019/10/30/08c99736cfdb4422bffcf711c8f642a 2_100.pdf.

True, S., 2019. "What's the Latest on Medicare Drug Price Negotiations?" Henry J. Kaiser Family Foundation, https://www.kff.org/medicare/issue-brief/whats-the-latest-on-medicare-drugprice-negotiations/.

Tulum, Ö., 2018. Innovation and Financialization in the U.S. Biopharmaceutical Industry. PhD dissertation, University of Ljubljana.

Tulum, Ö., Lazonick, W., 2018. "Financialized Corporations in a National Innovation System: The U.S. Pharmaceutical Industry," International Journal of Political Economy 47, 3-4: 281316. https://doi.org/10.1080/08911916.2018.1549842.

Tulum, Ö., Andreoni, A., Lazonick, W., 2022. "Innovation, Financialization, and Productivity in UK Big Pharma: AstraZeneca and GlaxoSmithKline," Project on Governance of Financialisation, Innovation, and Productivity in UK Manufacturing (forthcoming).

US Department of Health and Human Services, 2021, "Comprehensive Plan for Addressing High Drug Prices: A Report in Response to the Executive Order on Competition in the American Economy," Office of the Assistant Secretary for Planning and Evaluation, September 9, https://aspe.hhs.gov/reports/comprehensive-plan-addressing-high-drug-prices.

US House Committee on Ways and Means, 2019. "A Painful Pill to Swallow: U.S. vs. International Prescription Drug Prices," US House of Representatives, September, https://waysandmeans.house.gov/media-center/press-releases/ways-and-means-committeereleases-report-international-drug-pricing.

US House of Representatives Committee on Oversight and Reform, 2021a, "Drug Pricing Investigation: Industry Spending on Stock Buybacks, Dividends, and Executive Compensation, 
Staff Report," July, https://oversight.house.gov/news/press-releases/chairwoman-maloneyreleases-staff-report-showing-pharmaceutical-industry-spends .

US House of Representatives Committee on Oversight and Reform, 2021b, "Drug Pricing Investigation: Majority Staff Report," December, https://oversight.house.gov/news/pressreleases/chairwoman-maloney-releases-staff-report-showing-pharmaceutical-industry-spends.

Wapner, J., 2017. "Understanding the hidden villain of Big Pharma: pharmacy benefit managers," Newsweek, March 17, https://www.newsweek.com/big-pharma-villain-pbm-569980. 